Portland State University

PDXScholar

$1-1-2011$

\title{
Elemental and Isotopic Measurements on Palladium After Heavy Water Electrolysis
}

Mathieu Jean Valat

Portland State University

Follow this and additional works at: https://pdxscholar.library.pdx.edu/open_access_etds Let us know how access to this document benefits you.

\section{Recommended Citation}

Valat, Mathieu Jean, "Elemental and Isotopic Measurements on Palladium After Heavy Water Electrolysis" (2011). Dissertations and Theses. Paper 60.

https://doi.org/10.15760/etd.60

This Thesis is brought to you for free and open access. It has been accepted for inclusion in Dissertations and Theses by an authorized administrator of PDXScholar. Please contact us if we can make this document more accessible: pdxscholar@pdx.edu. 
Elemental and Isotopic Measurements on Palladium

After Heavy Water Electrolysis

by

Mathieu Jean Louis Adrien Valat

A thesis submitted in partial fulfillment

of the requirements for the degree of

Master of Science

in

Physics

Thesis Committee:

John Dash

Erik Sánchez

Peter Leung

Portland State University 


\section{ABSTRACT}

This study gives the details about several experiments done in Eugene Mallove Laboratory for New Energy Research. Three experiments are presented and discussed in detail with different type of microscopes and mass spectrometry techniques. Also inspired by work done by Rolison and O'Grady [2], the other part of this study presents the variation of isotopic abundance after experiments on palladium cathode immersed in a heavy water electrolyte. This original inspiring paper has been published through proceedings of the first edition of International Conference on Cold Fusion held in Washington D.C. in 1989. In other words, both works provides similar evidence of an isotopic variation before and after low energy nuclear experiments. By measuring the variation in isotopic concentration, before and after electrolysis, these measurements provide insight for how the low energy nuclear phenomenon occurs.

Scanning electron microscopes are used in the first part to provide high resolution, high magnification images of the electrodes. They show the morphology the topology of the cathode after experiment. An energy dispersive mass spectrometer is used to provide elemental composition of the cathode and provide a second independent measurement of elemental composition of the cathode. The presented isotopic measurements are made with a secondary ion mass spectrometer. 


\section{ACKNOWLEDGMENTS}

This research have been supported by John Dash and his laboratory, Eugene Mallove Laboratory for New Energy Research. I want to thank you John for his hospitality, his perseverance in this unique field of research. I want to show here my deep respect to his generosity in the effort he makes to put the outcome of his research to the public.

I also want to thank you Erik Sánchez and the team of the Nanotechnology and Near- field Microscopy Laboratory. I met talented, humble and openminded individuals that changed my perception of research. In addition, Erik showed me an innovative approach of management that let the student evolve and meet the inherent requirement of this work with serenity and responsibility in a collaborative and virtuous atmosphere.

This acknowledgment cannot avoid the excellent support provided by the department and the faculty team. So many vibrant minds gathered knowledge and brought interest to me up to an unknown level of mind outburst. The classes I had the opportunity to attend changed to a fundamental level my perception of nature. 


\section{TABLE OF CONTENTS}

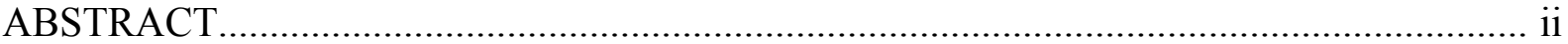

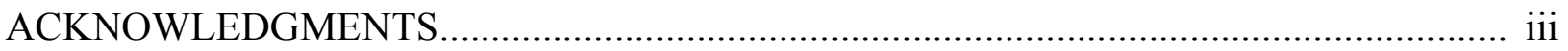

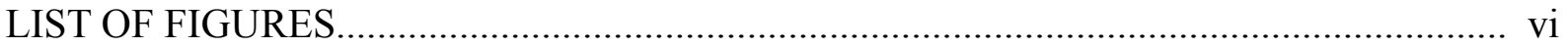

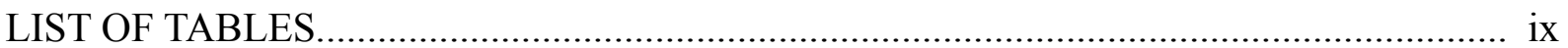

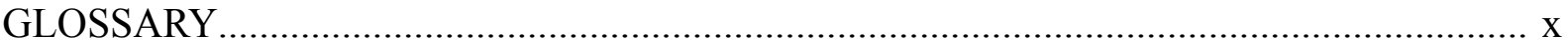

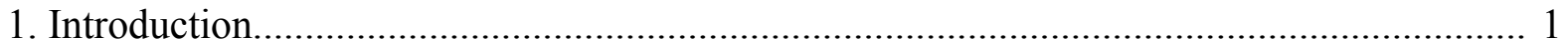

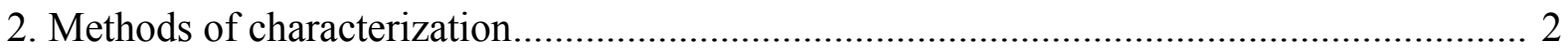

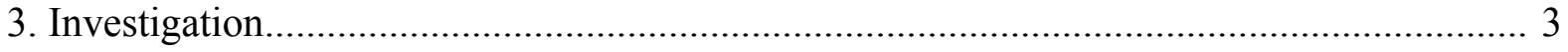

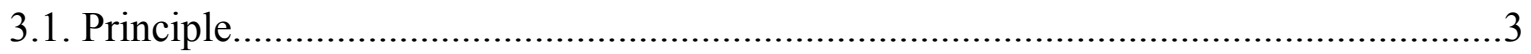

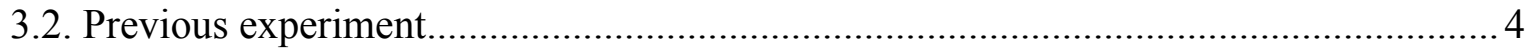

3.3. Evaluation of the energy released by the cells...................................................... 9

3.4. Characterization of the experiment.................................................................... 10

3.5. Practice of the SIMS on previous experiment........................................................16

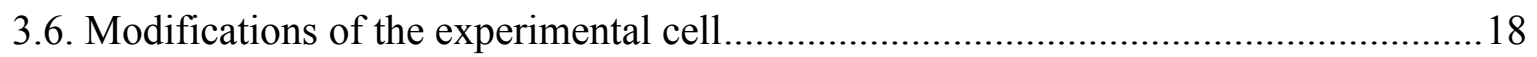

4. Description of the experiments.................................................................................. 20

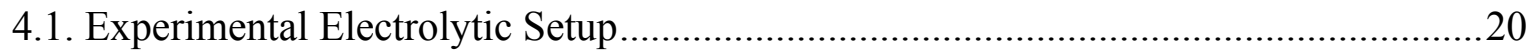

4.2. First experiment

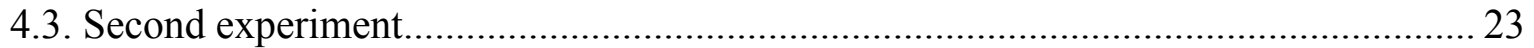

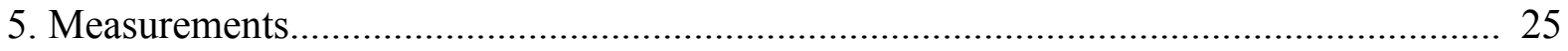

6. Study of features on the surface of the electrode.............................................................. 29

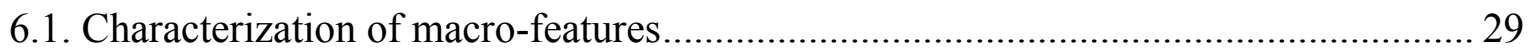


6.2. Characterization of micro-features.................................................................... 31

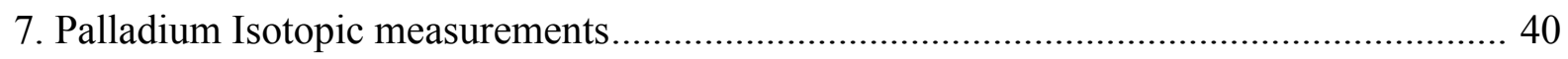

7.1. Evaluation of the milling rate produced by the ion gun......................................... 40

7.2. Incompatibility of the sputtered platinum........................................................ 42

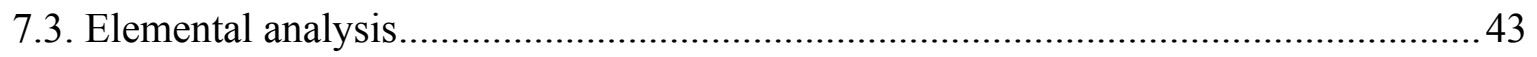

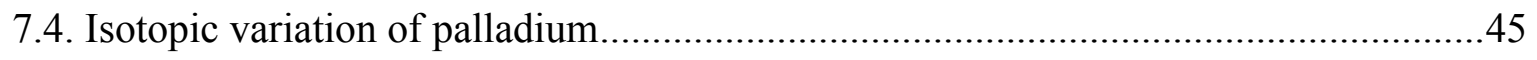

8. Conclusion...................................................................................................... 54 


\section{LIST OF FIGURES}

Figure 1: Schematic of the cell commonly used in our laboratory...... .5

Figure 2: Temperature measurements of each cell at different locations on the cell beaker. We can see how the experimental cell temperature reached higher temperature than the control cell continuously after the first 200 minutes.

Figure 3: Comparative measurements of temperature and voltage of the cells. We can see the adjustment of potential on the power supply and the differences of evolution of the temperatures. The current is constantly maintained to $3.5 \mathrm{~A}$ by the power supply..... 8

Figure 4: SEM picture of a feature at 2,400x showing the shape of a common feature found on the surface of cathodes.

Figure 5: EDS result of a feature on the surface of the electrode. a) Corresponding SEM image. b) Quantitative elemental analysis results. c) EDS spectrum of the zone.

Figure 6: EDS result of the another feature on the surface of the electrode. a) SEM image of

the zone. b) Quantitative elemental analysis results. c) EDS spectrum of the zone. 12 Figure 7: SEM picture of the surface the the electrode at 1,000 magnification. The scale bar is $50 \mu \mathrm{m}$ long. 13

Figure 8: SEM picture of the surface the the electrode at 5,000 magnification. The scale bar is $10 \mu \mathrm{m}$ long. 14

Figure 9: SEM picture of the bottom of the feature at 25,000 magnification. The scale bar is $2 \mu \mathrm{m}$.

Figure 10: Example of millings made on the surface. The milling pattern is represented in red and is $50 \mu \mathrm{m}$ in width. A solid square is milled on a platinum stack on the right side. 18

Figure 11: Schematic of the cell showing the main parts constituting the apparatus. 21

Figure 12: Experimental measurements of experiment \#2. We can notice two main variations. The first one is because of the night and the other one because of the dislocation of the anode in the electrolyte.

Figure 13: Light microscope picture of changes in topography of the cathode

Figure 14: Light microscope images showing the change in topography.... .30

Figure 15: SEM picture of a hole on the surface of the cathode. .32 
Figure 16: EDS microanalysis of a feature on the surface of the cathode showing high concentration of silver..

Figure 17: EDS microanalysis of the copper dots. a) Image if rhe location the spectrum is originated from. b) Elemental results of the microanalysis. c) Spectrum of the location analyzed.

Figure 18: SEM picture of a copper dot at $40 \mathrm{kx}$. 36

Figure 19: Microanalysis on and off the copper dots. On the upper spectrum the copper is present when the electron beam is pointing directly to the feature whereas it reduces drastically next to it.

Figure 20: SIMS analysis of a copper dot. The amount of $\mathrm{Cu}(63)$ is $69 \%$ and the $\mathrm{Cu}(65)$ is $31 \%$.

Figure 21: SEM picture of the vitrified carbon on the surface of the cathode at $4,2 \mathrm{kx}$. We can notice the change in contract at the center of each puzzle part. 39

Figure 22: SEM picture of a milling pattern made with the high energy ion beam. The pattern is $50 \mu \mathrm{m}$ in width. 41

Figure 23: SEM picture of a milling pattern made with high energy ion beam. The pattern is $50 \mu \mathrm{m}$ in width.

Figure 24: AFM analysis of an ion milling made at $500 \mathrm{pA}$. On the left picture we see the milled surface. On the upper right, we see the profile of the top line of the picture. On the last frame we see the results of the step analyzed giving a value close to $50 \mathrm{~nm}$.

Figure 25: SIMS Spectrum of the original palladium. The main peaks at the center are the gallium source. On the left the palladium shows its 6 isotopes. Are also present Fe, Al and small amounts of $\mathrm{Ti}$ and $\mathrm{Mg}$......

Figure 26: SIMS Spectrum of the loaded palladium. Fe is reduced, $\mathrm{Al}$ and $\mathrm{Mg}$ are enhanced. $\mathrm{K}$ peak is stronger. $\mathrm{Zn}$ is new...... 44

Figure 27: Example of data extraction from the measurements.

Figure 28: Graph showing the variation between the natural abundance and the calculated value of the loaded palladium.

Figure 29: Graph showing the calculated isotopic exchange of Pd loaded on April 2011. This shows for each isotope the percentage exchanged between the natural abundance and the 
corrected value of given by the calculation....................................................................50

Figure 30: Graph showing the calculated isotopic exchange of loaded Pd. This shows for each isotope the percentage exchanged between the natural abundance and the corrected value

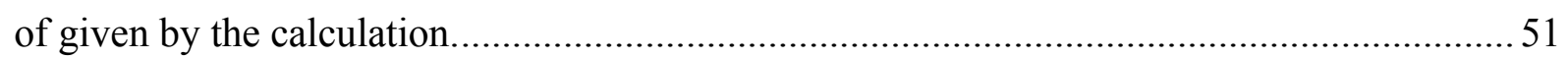

Figure 31: Graph showing the calculated isotopic exchange of Pd loaded on April 2011. This shows for each isotope the percentage exchanged between the natural abundance and the corrected value of given by the calculation.....................................................................52 


\section{LIST OF TABLES}

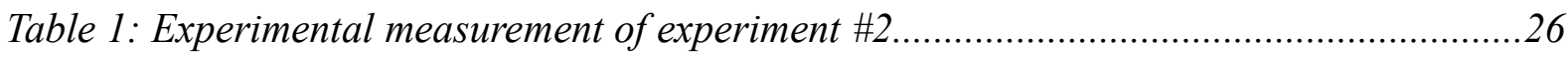
Table 2: Results of the evaluation of the isotopic concentration. The variation of Pd-102 is not evaluated. The last column gives the corrected value of the experimental cell following the trend given by the measurements on the control cell...........................................48

Table 3: Calculation of ratios for the three main isotopes of palladium................................53 


\section{GLOSSARY}

EDS: Energy-dispersive X-ray spectroscopy is an analytical technique used for the elemental analysis or chemical characterization of a sample. It is one of the variants of $\underline{X-r a y}$ fluorescence spectroscopy which relies on the investigation of a sample through interactions

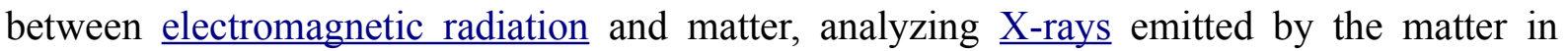
response to being hit with charged particles (electrons). Its characterization capabilities are due in large part to the fundamental principle that each element has a unique atomic structure allowing X-rays that are characteristic of an element's atomic structure to be identified uniquely from one another. (Source: Wikipedia)

SEM: A scanning electron microscope is a type of electron microscope that images a sample by scanning it with a high-energy beam of electrons in a raster scan pattern. The electrons interact with the atoms that make up the sample producing signals that contain information about the sample's surface topography, composition, and other properties such as electrical conductivity. (Source: Wikipedia)

SIMS: Secondary ion mass spectrometry is a technique used in materials science and surface science to analyze the composition of solid surfaces and thin films by sputtering the surface of

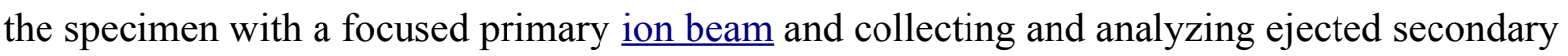
ions. These secondary ions are measured with a mass spectrometer to determine the elemental, isotopic, or molecular composition of the surface. SIMS is the most sensitive surface analysis technique, being able to detect elements present in the parts per billion range. (Source: Wikipedia) 


\section{Introduction}

On March 23 $3^{\text {rd }} 1989$, two Chemistry researchers, Stanley Pons and Martin Fleischmann, held a press conference in Salt Lake City claiming results and interpretation of a physical phenomenon that had the potential to change the contemporary energy paradigm. Using a classic electrolytic technique of deuterium loading of palladium, they claimed creation of excessive energy generated from the cathode that cannot be explained by conventional chemical effects [1]. Their thoughts were directed to an unknown nuclear process, that would take place in the palladium lattice leading to a radically different way to produce thermonuclear fusion reactions. The effect on the scientific community was unprecedented and lead to high skepticism due to their interpretations and the lack of reproducibility of their experimental results.

After these epic claims brought by Stanley Pons and Martin Fleischmann in March 1989 [1], Rolison and O'Grady studied anomalous variation in mass/charge of palladium electrolyzed in both light or heavy water using a time of flight secondary ion mass spectrometer (TOF-SIMS) [2]. Soon after, the conclusion of their research was heavily debated, mainly because of the correlation between the physical phenomenon that occurred during their experiment and the interpretation published in their paper. Nowadays, their conclusions remain valid and their peers consider this paper as one of the main research contribution to the field of low energy nuclear research. However, since then, no other paper has been published on this subject trying to reproduce these results. 


\section{Methods of characterization}

The sample is analyzed before and after the electrolysis with a wide range of devices. This characterization intends to define features present on the surface of the sample. First, a light microscope was used to picture large size features.

Secondly, using a SEM (JEOL model 6300F) and the coupled EDS (Oxford with a Si window, doped Li), we define the shape of the feature and its chemical composition. The JEOL SEM is a field emission microscope capable of a $10 \mathrm{~nm}$ resolution and the SIMS has a resolution of 0.2 atomic mass unit. Two other SEM have been used to characterize the features. These SEM are a ZEISS SIGMA, which is capable of a resolution of up to $1.3 \mathrm{~nm}$. The coupled EDS is a INCA OXFORD $50 \mathrm{~mm}^{2}$ ultra-thin window. And the other one is an FEI Sirion FEG XL30. It is capable of $1.5 \mathrm{~nm}$ resolution and has an INCA OXFORD EDS.

Thirdly, we define the isotopic composition with the SIMS (FEI 611 coupled with an EXTREL IIIxp). The ion gun is equipped with a gallium source. This instrument gives us the capacity to define what elements are present inside the sample based on atomic mass (detailed explanation in Glossary). Thus, it gives a different indication of the composition and the isotopes present, and helps to inform us about the phenomena that occurred during the experiment. 


\section{Investigation}

\subsection{Principle}

Using electrolysis, the main objective is the creation of hydrides of deuterium on the surface and throughout the bulk of the palladium cathode. The palladium crystalline structure is cubic face centered (CFC). The effect of hydrogenation into this crystal structure is obtained by electrochemical loading. Electrochemical loading is an effect where hydrogen isotopes are forming hydrides by penetrating the hosting palladium crystal lattice. By losing their only electron as a consequence, they place themselves at octahedral sites. This creates a binary system $\mathrm{Pd} / \mathrm{D}$, that varies with the concentration of deuterons that penetrate the surface of the palladium crystal lattice [3]. Three phases separate these variations of deuteron density. The first phase alpha $(\alpha)$ starts form a concentration of 0 to $10 \%$ of deuterium; the second phase beta $(\beta)$ starts at $10 \%$ and ends at $70 \%$; and finally the third one gamma $(\gamma)$ is greater

$70 \%$. However, when the binary system is in its $\beta$ phase - especially starting at $80 \%$, the concentration is acknowledged to be sufficient to induce reactions producing heat from a non chemical effects [4].

While trying to study another aspect of this phenomenon, Rolison and O'Grady [2] showed a change in specific isotopes on electrolyzed palladium depended on the use of light water or heavy water. Because they did not find variation of isotopic concentration between the original and the palladium electrolyzed with light water, this research will only compare the original palladium with the electrolyzed one in heavy water. However, we will try to determine at which depth this variation occurred in what percentage changed using the milling 
capacity of the ion gun. Therefore it is necessary to evaluate if the current experimental setup used in the laboratory [5] will be compatible the SIMS.

\subsection{Previous experiment}

Before doing experiments with the insight of measuring variation in isotopic concentration, it was necessary to study the previous work performed in our laboratory. This step is important to find a background knowledge we can study first then adapt to prodice a different aspect of the current results produced by the laboratory.

The electrolysis performed in our laboratory since 1989 typically uses platinum anode and palladium cathode [5]. These two electrodes are attached to two platinum wires and are immersed into a solution made of heavy water and sulfuric acid. The container is a Berzelius beaker and the cap made of Teflon which hold the recombination catalysts and the two Pt wires. The palladium is cold rolled before electrolysis allowing for an increase in acceptance of the hydrogen isotopes [6].

For the first study, we tried to reproduce results of an experiment made in Salt Lake City in 2008 [7]. The peculiarity of this experiment was the use of battery fluid to ionize the electrolyte. Commercial battery fluid is diluted sulfuric acid, the variation of specific gravity reduces from 1.84 to 1.26 . The reason of this is because no sulfuric research grade acid was available during the experiment at Salt Lake city, so it was decided to use battery fluid for its commonality. The results were interesting and led us to try to reproduce these results.

This experiment was made on February 2010 using two pieces of palladium (Alpha Aesar Pd foil 99.9\% Lot \#11514), one for the control and the other for the experimental cell. 
Both have been cold rolled from their original $0.5 \mathrm{~mm}$ thickness to $0.25 \mathrm{~mm}$. The weight of the cathodes are $0.8 \mathrm{~g}$ and $0.82 \mathrm{~g}$. A hole is made at one end of either pieces with a steel spike to hook each piece to its Pt wires. The control cell electrolyte is made of $75 \mathrm{~mL}$ of tap water and $25 \mathrm{~mL}$ of $\mathrm{H}_{2} \mathrm{SO}_{4}$, the total weight of the cell is $344.5 \mathrm{~g}$. The experimental cell is made of $50 \mathrm{~mL}$ of deuterium oxide $\left(\mathrm{D}_{2} \mathrm{O} 99.9 \%\right.$ from Aldrich Chemicals, stock \#O8304CJ) and $50 \mathrm{~mL}$ of common battery fluid (Colonial Chemical Stock\#44000). The DC power supply is a HP 6264B. The electrode after cold rolling is $8 \mathrm{~mm}$ in width and $28 \mathrm{~mm}$ long. The experiment has been run for about 22 hours with a current density of approximately $800 \mathrm{~mA} / \mathrm{cm}^{2}$.

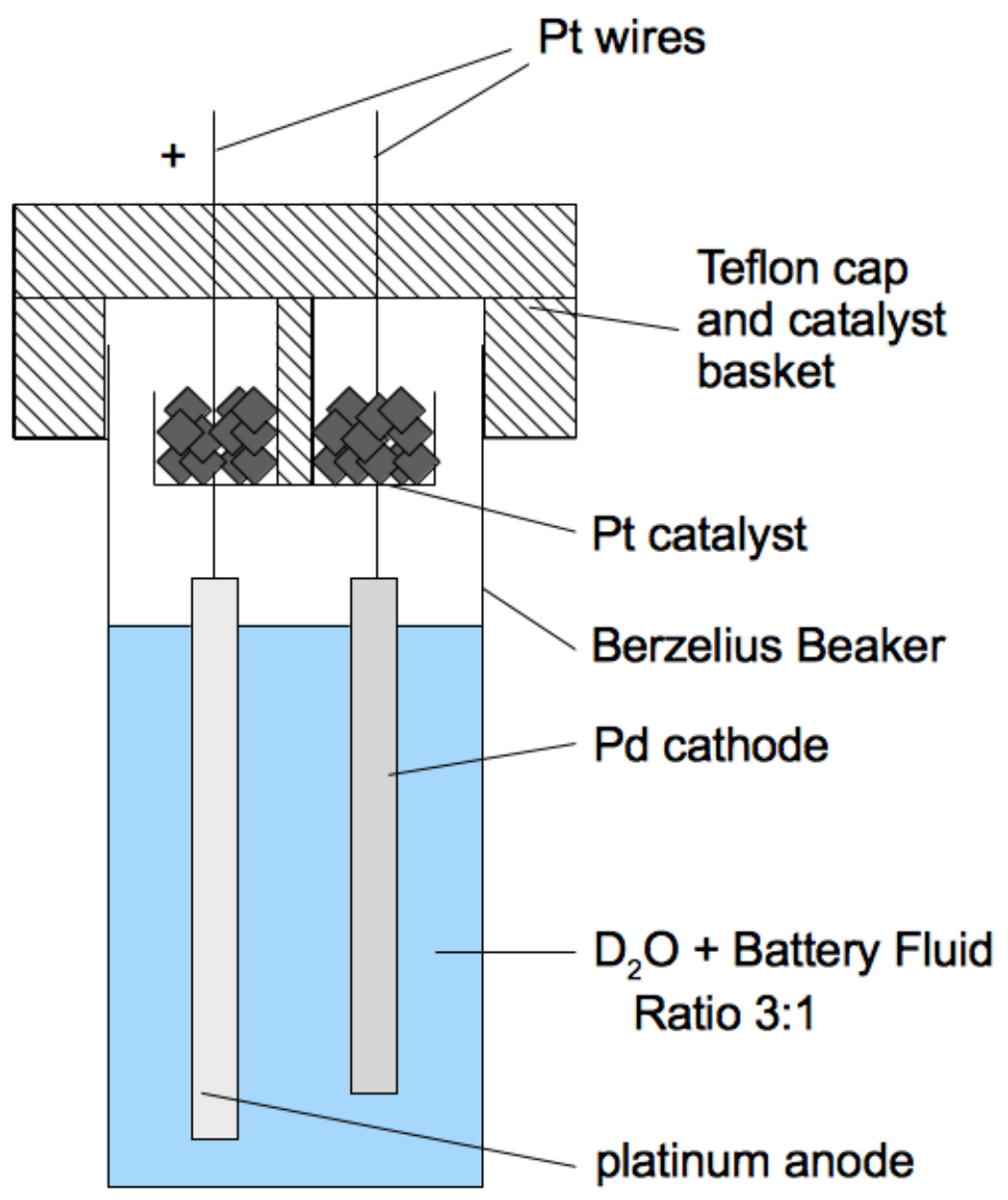

Figure 1: Schematic of the cell commonly used in our laboratory. 
Figure 1 shows a schematic of the experimental apparatus. The following Figure 2 and 3 give the measurements of this experiment given by a thermocouple placed at different places on the beaker and the potential applied to each cell. Two hours after the experiment has started, we assumed the loading reached the beta phase at which time the potential is readjusted to $4.0 \mathrm{~V}$. The weight of each cell after the electrolysis are $316.12 \mathrm{~g}$ for the control cell and $296.50 \mathrm{~g}$ for the experimental cell. The variation of weight is $28.76 \mathrm{~g}$ for the control and $41.96 \mathrm{~g}$ for the experimental cell. Hence, the experimental cell evaporated almost 50\% more electrolyte than the control cell. 


\section{Measurement Chart for the Control Cell}

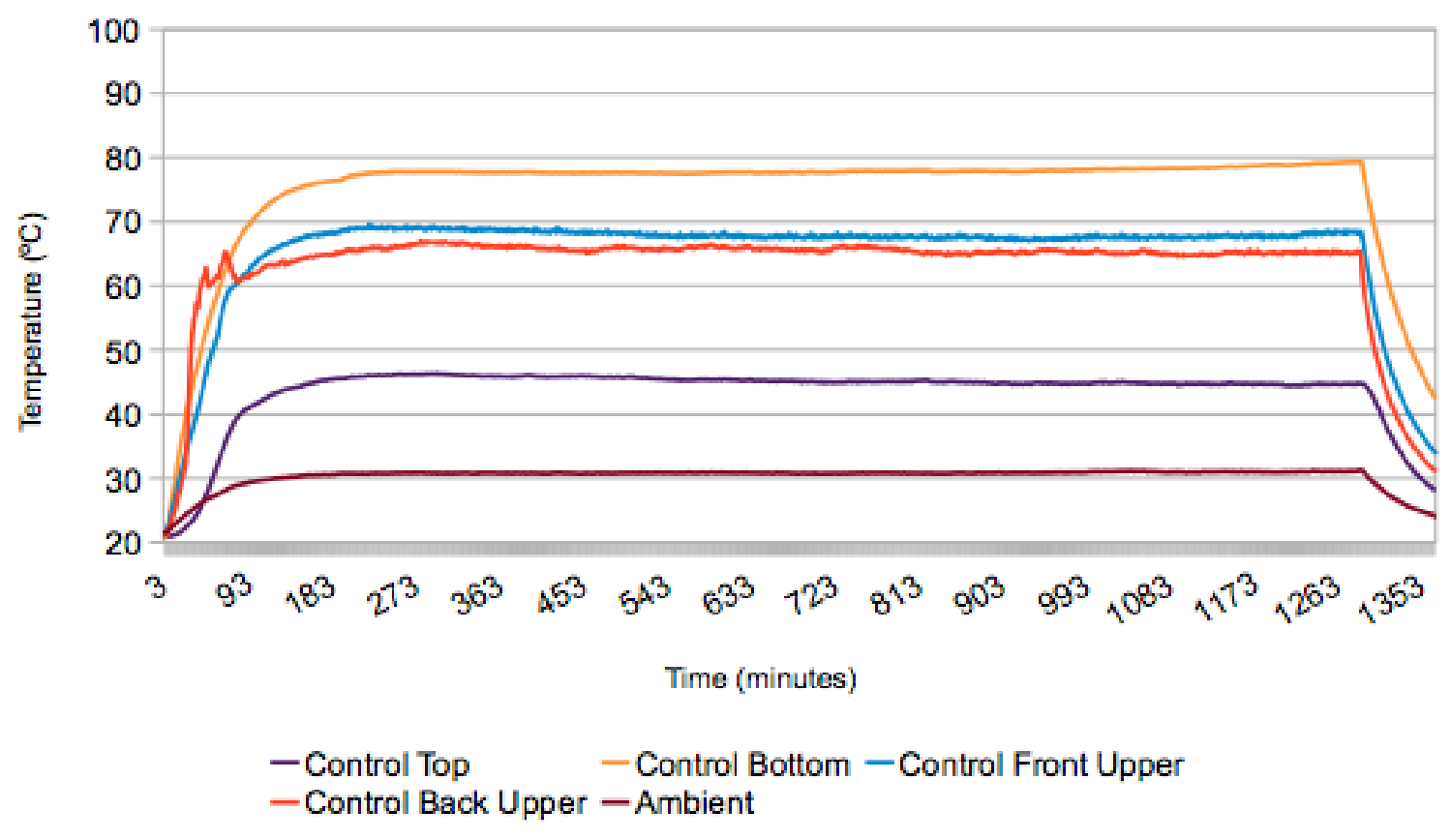

\section{Measurement Chart of the Experimental Cell}

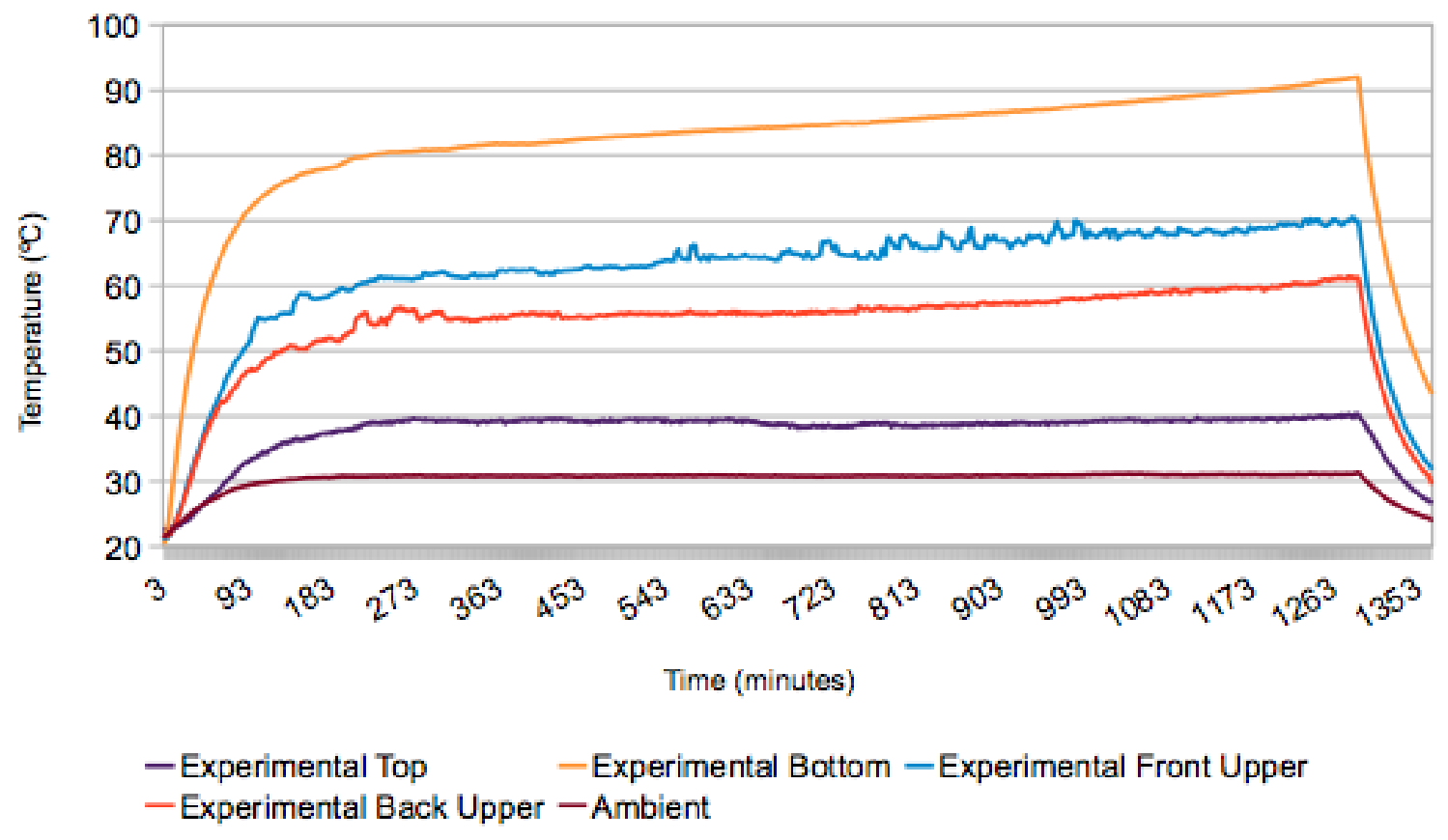

Figure 2: Temperature measurements of each cell at different locations on the cell beaker. We can see how the experimental cell temperature reached higher temperature than the control cell continuously after the first 200 minutes. 
Measurement Chart of Temperatures

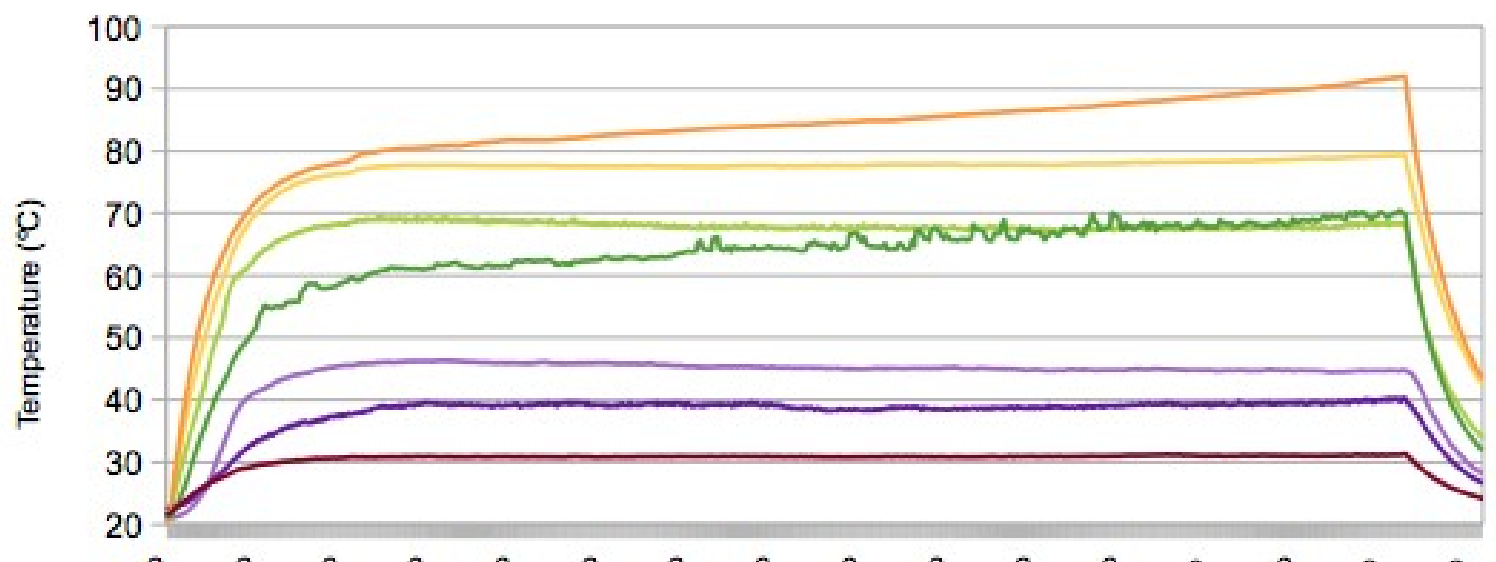

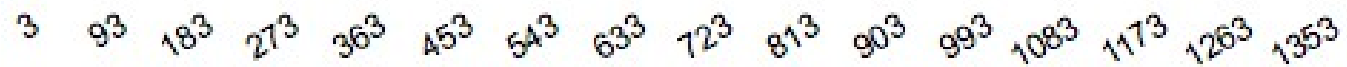

Time (minutes)

- Control Top $\quad$ - Control Bottom $\quad$ - Control Front Upper
- Experimental Top - Experimental Bottom - Experimental Front Upper
-Ambient

Measurement Chart of applied Voltages

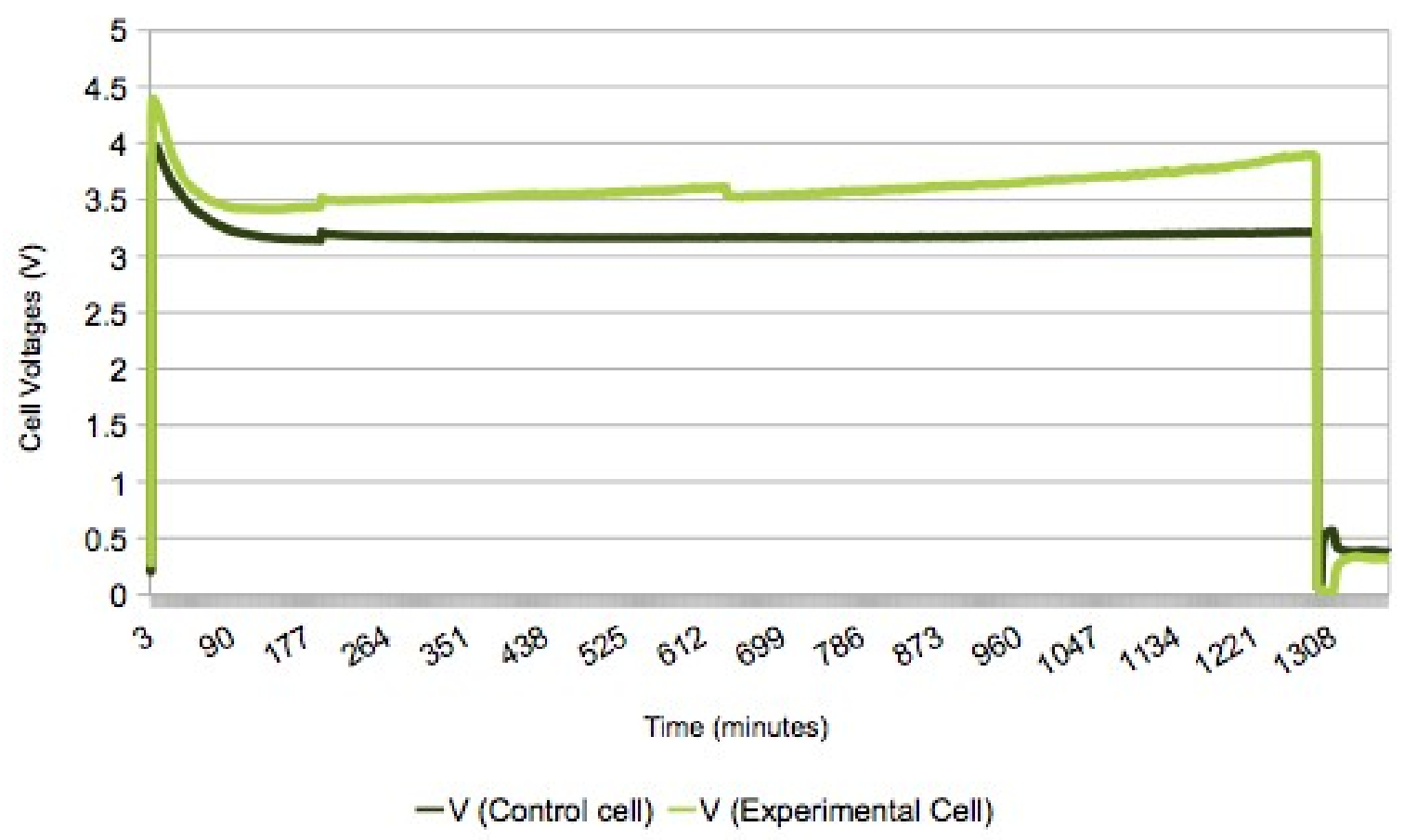

Figure 3: Comparative measurements of temperature and voltage of the cells. We can see the adjustment of potential on the power supply and the differences of evolution of the temperatures. The current is constantly maintained to 3.5A by the power supply. 


\subsection{Evaluation of the energy released by the cells}

For this calculation we will consider the battery fluid is composed of $46 \%$ of $\mathrm{H}_{2} \mathrm{O}$ (Specific grav. Of sulfuric acid is 1.84 and battery fluid is 1.26). During the experiment $41.96 \mathrm{~g}$ of $\mathrm{D}_{2} \mathrm{O}+\mathrm{H}_{2} \mathrm{O}$ and $28.76 \mathrm{~g}$ of $\mathrm{H}_{2} \mathrm{O}+\mathrm{H}_{2} \mathrm{SO}_{4}$ were evaporated. No sulfuric acid is considered evaporated because its boiling point is above $300^{\circ} \mathrm{C}$. Using the specific recombination heat of light and heavy water, the calculated energy loss in each cell by evaporation is $645 \mathrm{~kJ}$ for the experimental cell and $471 \mathrm{~kJ}$ for the control cell.

$$
\frac{d H(\text { excess heat })}{d t}=\frac{\left(T_{e}-T_{a}\right)}{\left(T_{c}-T_{a}\right)} \times\left(V_{c} \times I\right)-\frac{d H_{c}}{d t}+\frac{d H_{e}}{d t}-\left(V_{e} \times I\right)
$$

$\mathrm{H} x$ : loss of electrolyte in the cell $x$.

Vx: potential applied to the cell $x$.

I: current applied to the cells.

Tx: temperature measured on the cell $x$.

Then, using the temperature of the electrolyte which is considered equal to the temperature at the bottom of each cell and the power input from the power supply, we obtain the difference of energy generated by each cell. The subtraction gives an approximate value of excessive power generated by the experimental cell of $0.93 \mathrm{~W}$. 


\subsection{Characterization of the experiment}

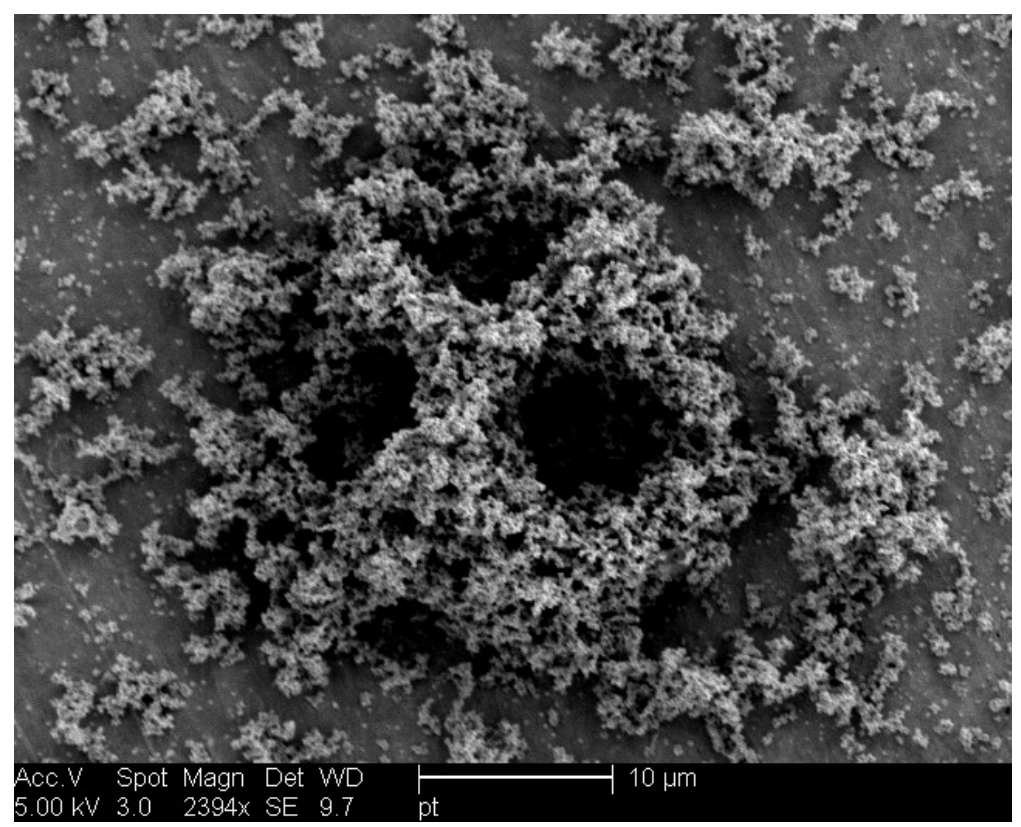

Figure 4: SEM picture of a feature at 2,400x showing the shape of a common feature found on the surface of cathodes.

The experiment presented previously has been analyzed using an SEM FEI Sirion equipped with a Oxford EDS. The acceleration voltage is varied from 5 to $20 \mathrm{keV}$.

Figure 4 shows typical features found throughout the surface of the palladium cathode. These features are commonly called hotspot or volcano in the laboratory and are subject of speculations. This formation is made of platinum coming from the anode. This type of feature will be extensively studied later in this Chapter. 


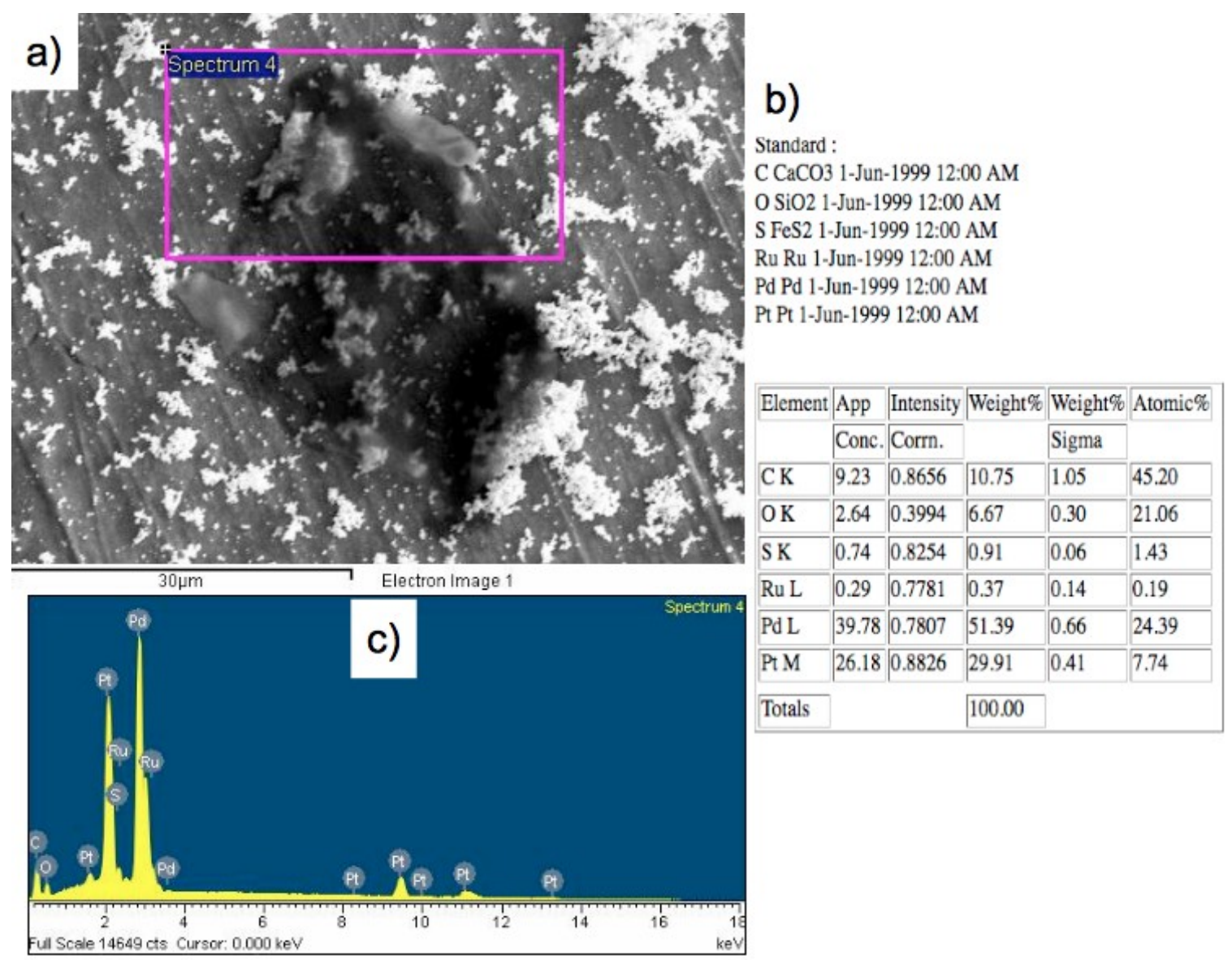

Figure 5: EDS result of a feature on the surface of the electrode. a) Corresponding SEM image. b) Quantitative elemental analysis results. c) EDS spectrum of the zone.

The analysis was interesting since it shows features taking the form of dark transparent shadow. This is probably a hole on the surface of the electrode. The SEM was only able to resolve it as a reduction of signal coming from it because of the low yield of secondary electron or faraday cup effect it involves. In order to produce wide range spectrum the beam must be set at $20 \mathrm{keV}$, but this acceleration voltage reduces greatly the capability to resolve topographical feature like this. The ruthenium found on the spectrum is artefactual. 


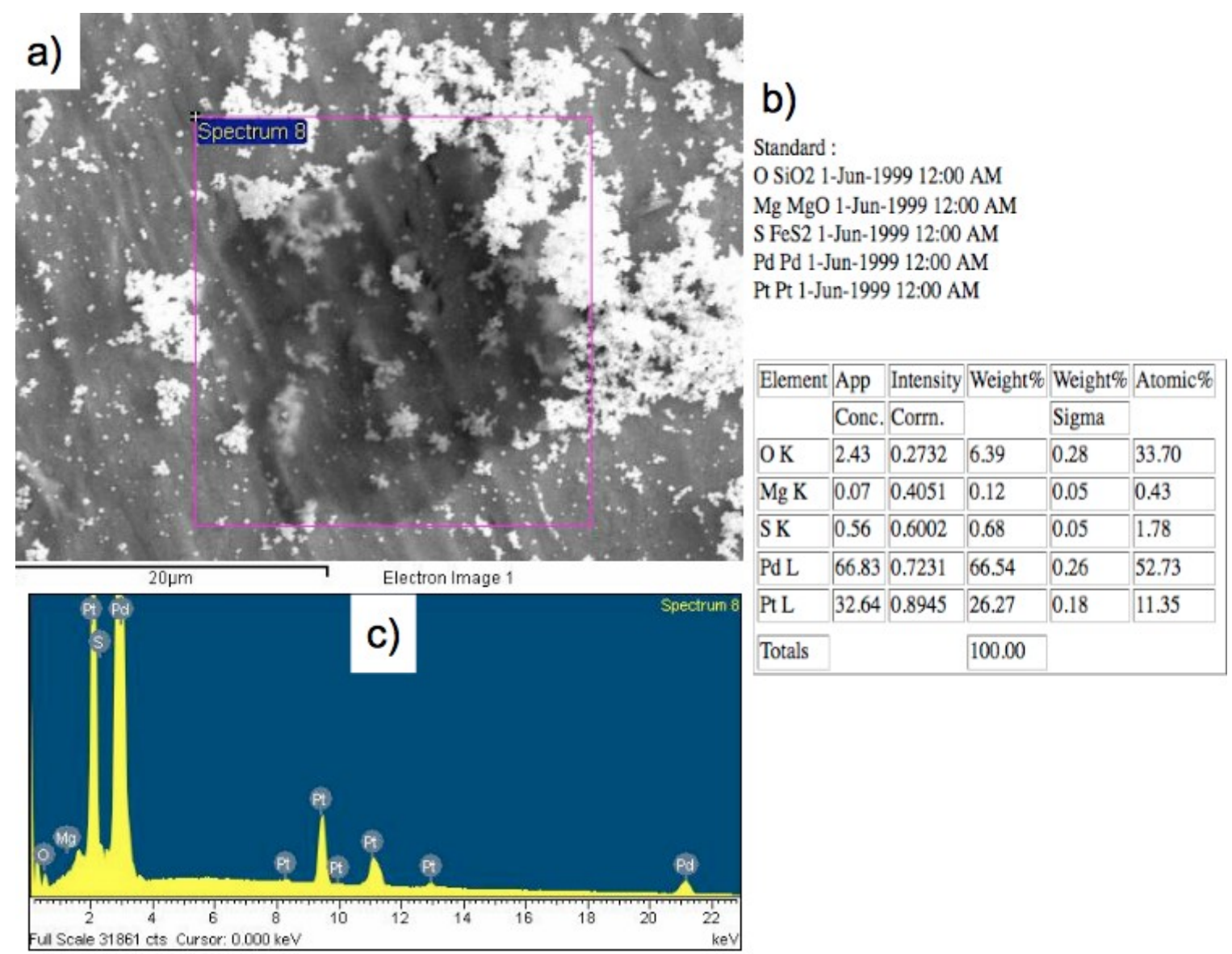

Figure 6: EDS result of the another feature on the surface of the electrode. a) SEM image of the zone. b) Quantitative elemental analysis results. c) EDS spectrum of the zone.

This spectrum reveals the same effect on another feature on the sample. From the chemical analysis, we can observe how the platinum is omnipresent on the palladium cathode. This platinum is coming from the anode and is brought by the electrochemical effect. The magnesium showed on the spectrum is also an artifact of the software and should not be taken in consideration because it is not present in the sample.

This part of the characterization is also important because we can get experienced with the measurement devices. Handling the measurements devices was an essential part of the project as well as defining how these features are created, and which details can be eventually 
changed in order to adapt the experiment to the characterization tools. It was necessary to study a sample made recently because of the contamination from the dust and various source change the surface composition analyzed with the SIMS. Using an electrode loaded in June 2010 the SEM showed how features are forming on the surface to the platinum electrode. The SIMS is used to do some test on the sample and see how its components react to the tool.

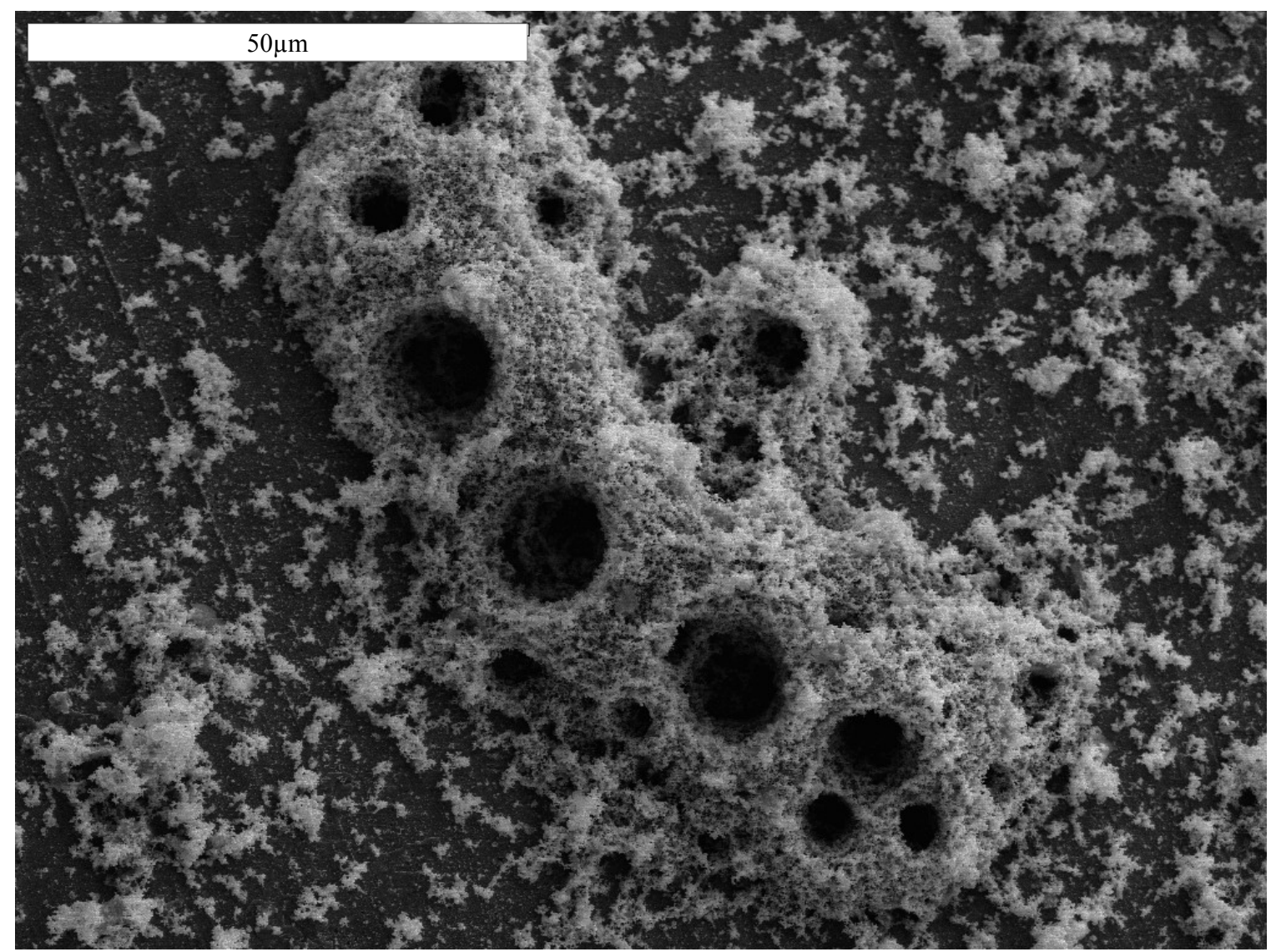

Figure 7: SEM picture of the surface the the electrode at 1,000 magnification. The scale bar is 50 um long.

As we can see in Figure 7 and 8, a formation is made of tiny particles that are agglomerating together on the surface and having the general shape of an volcano. The approximate diameter at the top of the formation is close to $8 \mu \mathrm{m}$ on average. We already noticed a composition of high platinum purity in previous spectra. 


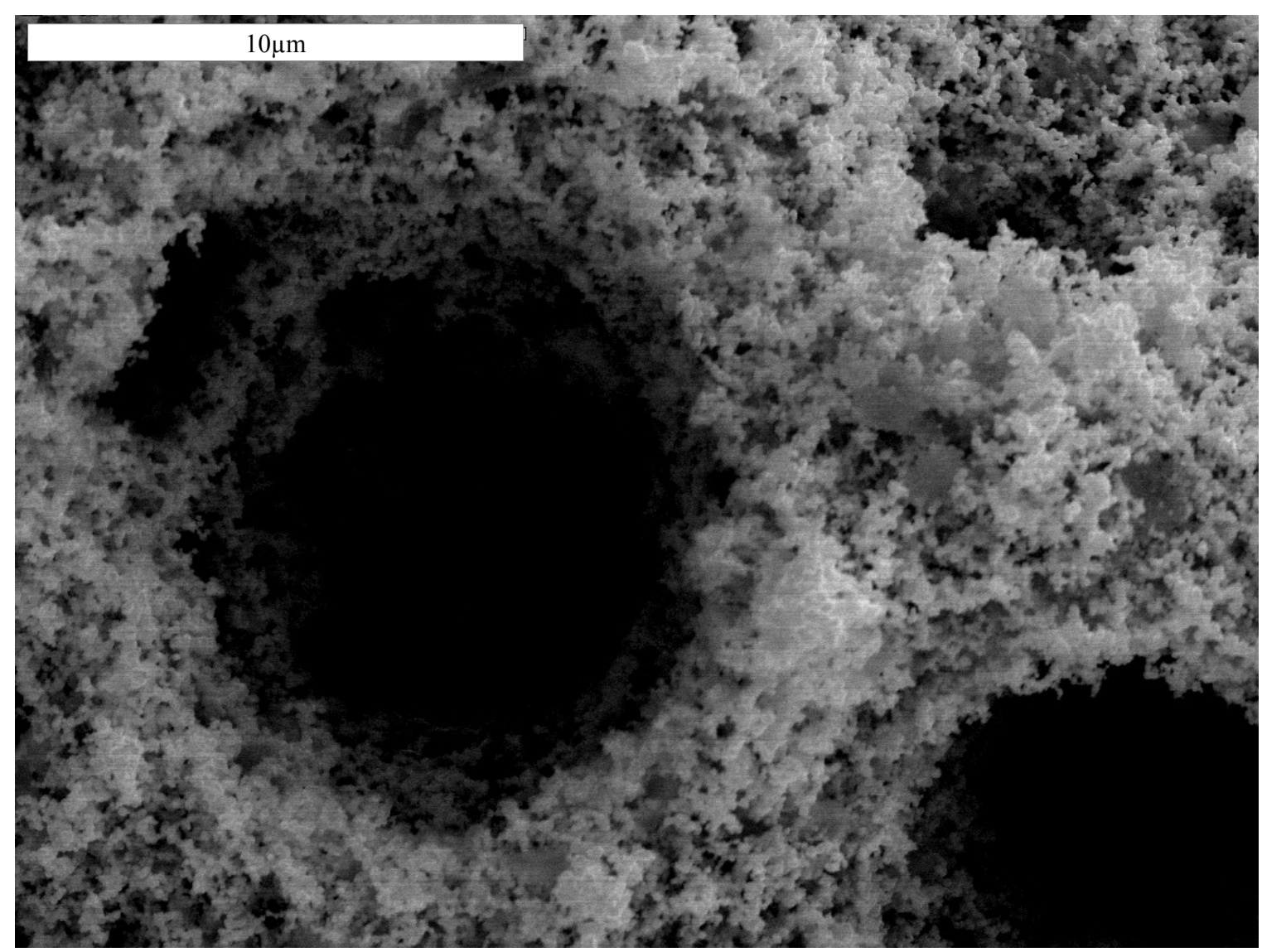

Figure 8: SEM picture of the surface the the electrode at 5,000 magnification. The scale bar is $10 \mu \mathrm{m}$ long.

Finally, the following Figure 9 shows us a closer look at what happened inside these volcanos during the experiment. This picture gives important indications about the nature of the changes that occurred. The feature at the bottom is approximately circular and $2.5 \mu \mathrm{m}$ in diameter. It shows a melted area with a waving irregular surface. We can clearly see that the very bottom is not the original surface because there is waving variations of this surface and the surroundings of the bottom shows a step. This step is irregular in circularity, especially on its upper half. Its direction is along the perpendicular axis to the surface of the electrode. It is not possible to define the height of this step, and no other angle of view is possible because this feature forms a Faraday cup. Taking the picture showed in Figure 9 was difficult. 
However, some platinum particles have been deposited after the phenomenon occurred.

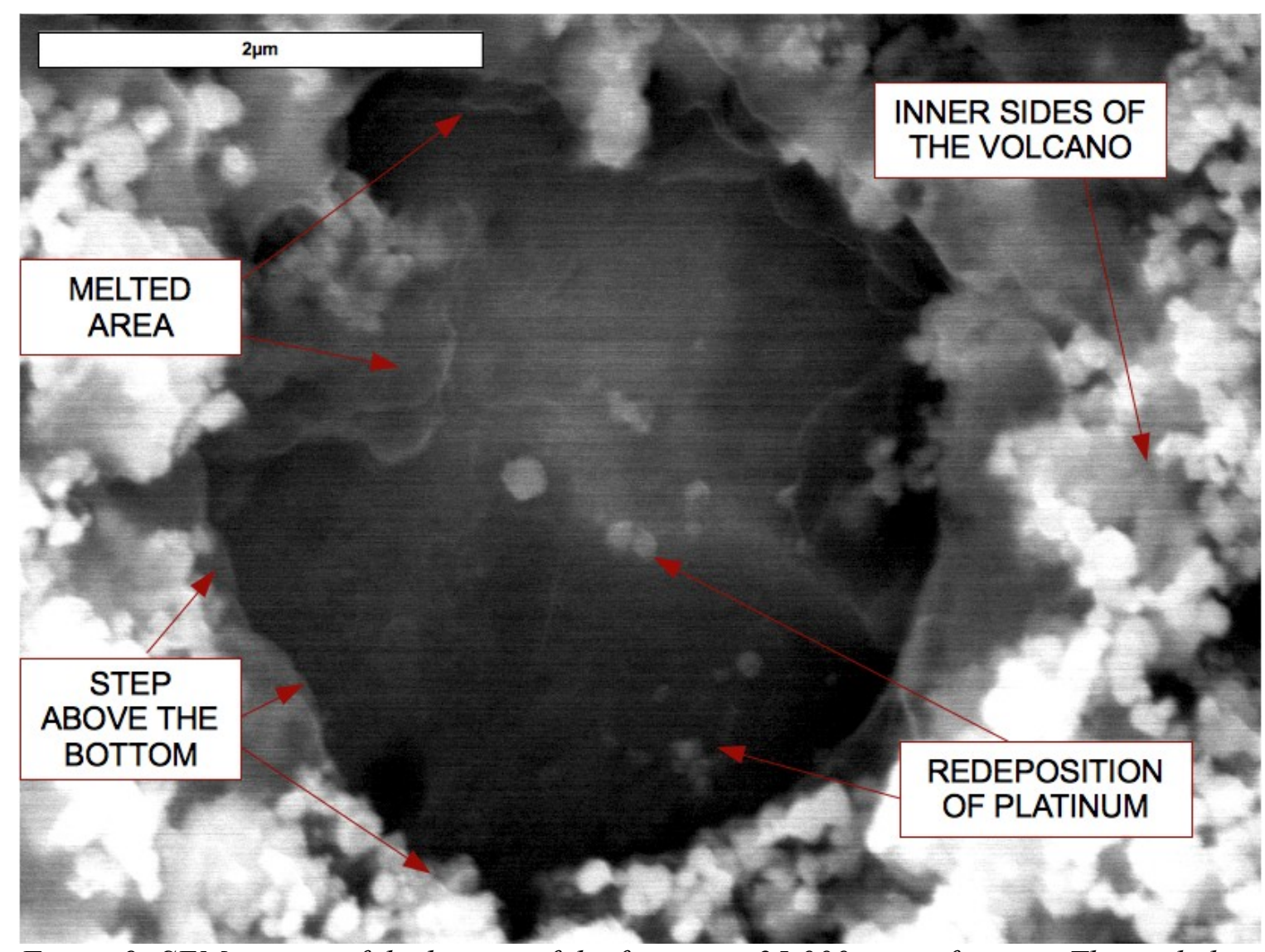

Figure 9: SEM picture of the bottom of the feature at 25,000 magnification. The scale bar is $2 \mu m$.

Finally, we performed two further fundamentally different characterizations using energy dispersive spectrometry (EDS) and secondary ion mass spectrometer (SIMS). The EDS technique involves X-ray generated by stimulated emission coming from the location where the SEM beam is shooting. The SIMS uses a quadrupole mass analyzer to separate the masses by resonant electric fields, which allow only the selected masses to pass through and be counted. Because the manner used to define the spectrometric mass of elements goes 
through completely different principle, these techniques can be used to confirm the elemental analysis by two independent methods.

The complementary aspect of these two spectrometric techniques allows us to verify if anomalous elements have been created or are coming from external source of contamination. If the natural isotopic abundance of the same location characterized by EDS measurement is identical or close to the standards, the element is more likely to be present at this location.

\subsection{Practice of the SIMS on previous experiment}

This device is extremely complicated and requires a lot understanding of the underlying physical operation. It was necessary to train myself on this device and gather sufficient knowledge to tune in it correctly, fix and produce reliable results. It is also important to find the right parameter of measurement for the palladium.

This SIMS is capable of measuring atomic mass from 1 to 200. But the higher part of the spectrum is hard to detect because of the difference of mass with the secondary ions generated by a lighter primary ion source like gallium (69 and 71 atomic mass unit). For instance, platinum has several isotopic masses from 191 to 198 atomic mass unit (AMU) and palladium has 6 isotopes from 102 to 110 AMU. Due to the mass difference, it was possible to resolve palladium but platinum was too heavy to be seen on the spectra produced by this lightweight source.

After several milling tests, the SEM showed how the sample reacted to the ion beam. Figure 10 shows two different patterns milled on the surface of the cathode borrowed from the 
laboratory. We can see the modification on the electro-deposited platinum, it shows how the ions changed the topography of the platinum. The EDS shows an important quantity of trapped gallium in this area.

Figure 10 shows a pattern milled on the surface of the cathode and a milled square on the top of a platinum stack deposited on the palladium. The pattern has been drawn in red and we can see the difference in texture between the milled surface and the original surface. The beam implants and build gallium ions on the platinum particles and get trapped on the surface of the cathode. Hence, it was necessary to avoid this effect for the isotopic measurements.

On the right side of Figure 10 we can see a test milling made with different primary ion beam intensities. Varying the beam current, we can change the quantity of ions sent to the sample. Starting at $3 \mu \mathrm{A}$ of beam current, the platinum deposition has been shaped by the gallium ions. A normal value of beam current is usually in tenth of nano-Ampères, therefore this necessary quantity of beam current is very important and cannot be used in further isotopic analysis because it degrades the surface and does not creates a uniform analysis of the surface. More detail of the milling of the pattern will be developed in the Chapter 7 as the isotopic measurements are more described. 


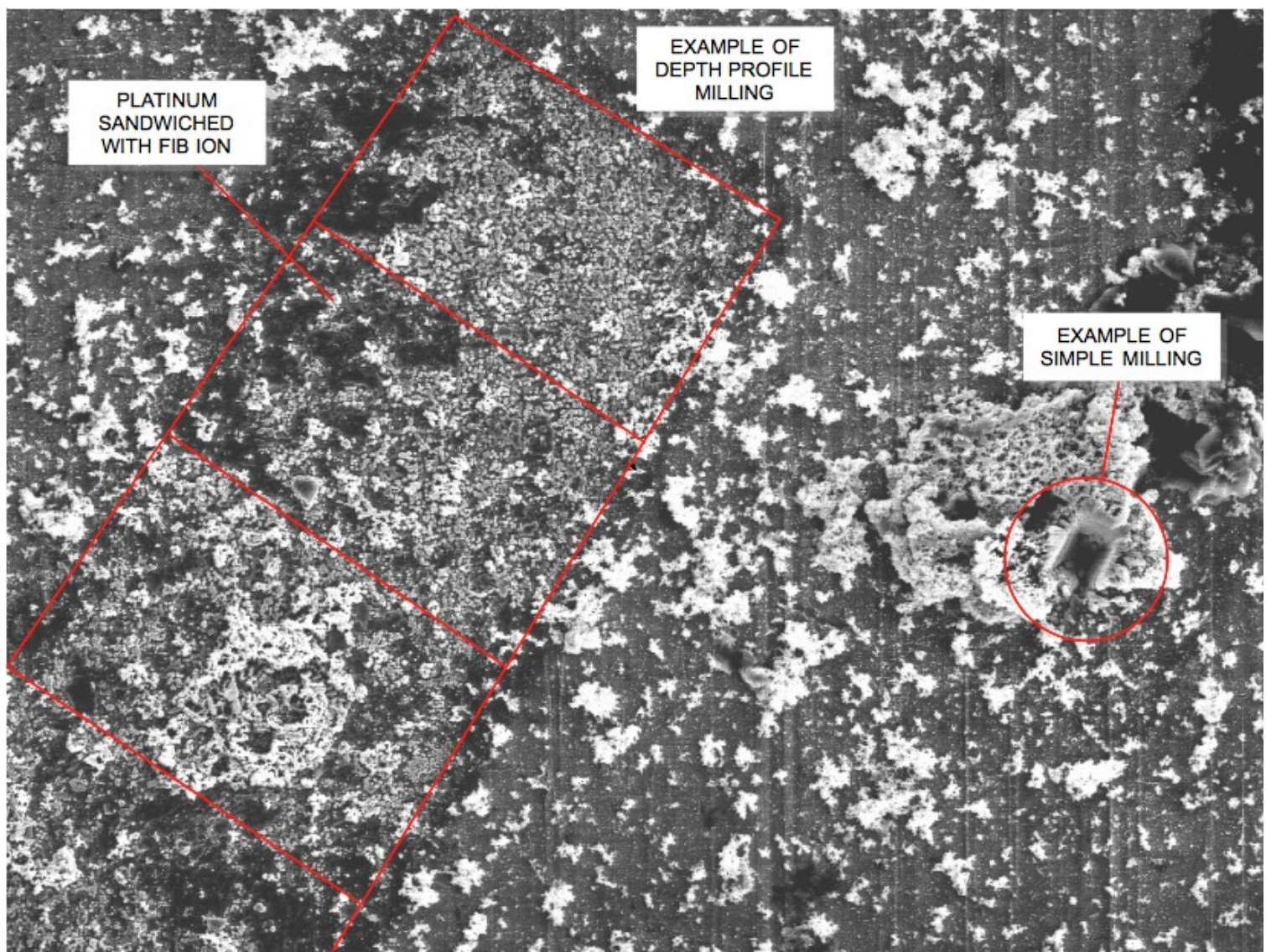

Figure 10: Example of millings made on the surface. The milling pattern is represented in red and is 50 $\mathrm{mm}$ in width. A solid square is milled on a platinum stack on the right side.

\subsection{Modifications of the experimental cell}

In terms of measurements, this project complements the two previously introduced spectrometry techniques. But the technology used to make the isotopic measurements of the substrate requires an ion gun to extract matter from the sample and generate secondary ions. If the surface is covered by platinum deposition, the accessible surface of palladium is reduced. Moreover, due to the shape of the features, any eventual hotspot will trap ions from the gun and cancel any generation of secondary ions at these places, for it is here where palladium should be most concentrated. 
Therefore, it is possible to make some modifications of the cell in order to adapt the experiment to the measurement devices. After discussions the option of using a carbon anode has been chosen [8]. Using carbon in its graphite form is fragile, it can be easily broken with sonicated bath of deionized water. It is also a very good conductor which is essential for the electrolysis.

Another aspect that would impact the results is the suppression of the platinum. If it is a necessary element to create highly energetic reactions, as it is used since the beginning of the study of this phenomenon by Pons and Fleischmann [1], suppressing would not make sense. This is why a platinum plasma deposition will be made for the second experiment with unfortunate implications as we will discover in the last part of this study.

Finally, because this experiment has been originally designed to be a proof of concept, some aspect are simplified. It is not necessary to do two cells because we are comparing the original Pd and the electrolyzed Pd to define the changes that occurred during the loading. The temperature can be checked manually and a thermocouple placed at the bottom of the cell to moniter the temperature of the electrolyte. 


\section{Description of the experiments}

The principle of this experiment is to define the modifications that occurred during the electrolysis by a quick analysis of the sample before the electrolysis. Then an extended characterization of the changes that occurred on the surface of the electrode. The other insight is to define quantitatively the variation of palladium isotopes before and after deuterium loading.

\subsection{Experimental Electrolytic Setup}

a) The cell

The electrolyte is prepared with deuterium oxide $\left(\mathrm{D}_{2} \mathrm{O} 99.9 \%\right.$ from Aldrich Chemicals, stock \#435767) and sulfuric acid $\left(\mathrm{H}_{2} \mathrm{SO}_{4}\right.$ from Fisher Scientific, Lot \#050994). The cell is composed of a beaker where the electrolyte is mixed in. Then the top part of the cell is introduced in the beaker. The distance between the two electrodes, is set by bending two platinum wires that hold each electrode of the setup (Platinum wire 1mm diameter from Alpha Aesar $99.95 \%$, stock \#10285). The cathode is connected to the negative polarity of the power supply and the anode to the positive. The temperature is checked every 30min with a thermocouple placed underneath the beaker. Some catalytic recombinants are placed on the top of the cell (Alumina pellets from Alpha Aesar, $\mathrm{Al}_{2} \mathrm{O}_{3}$ doped with $0.5 \%$ of Pt, Stock \#89106). This allows to recombine $\mathrm{D}_{2}$ and $\mathrm{O}_{2}$ gases when they form on the surface of the electrodes. 


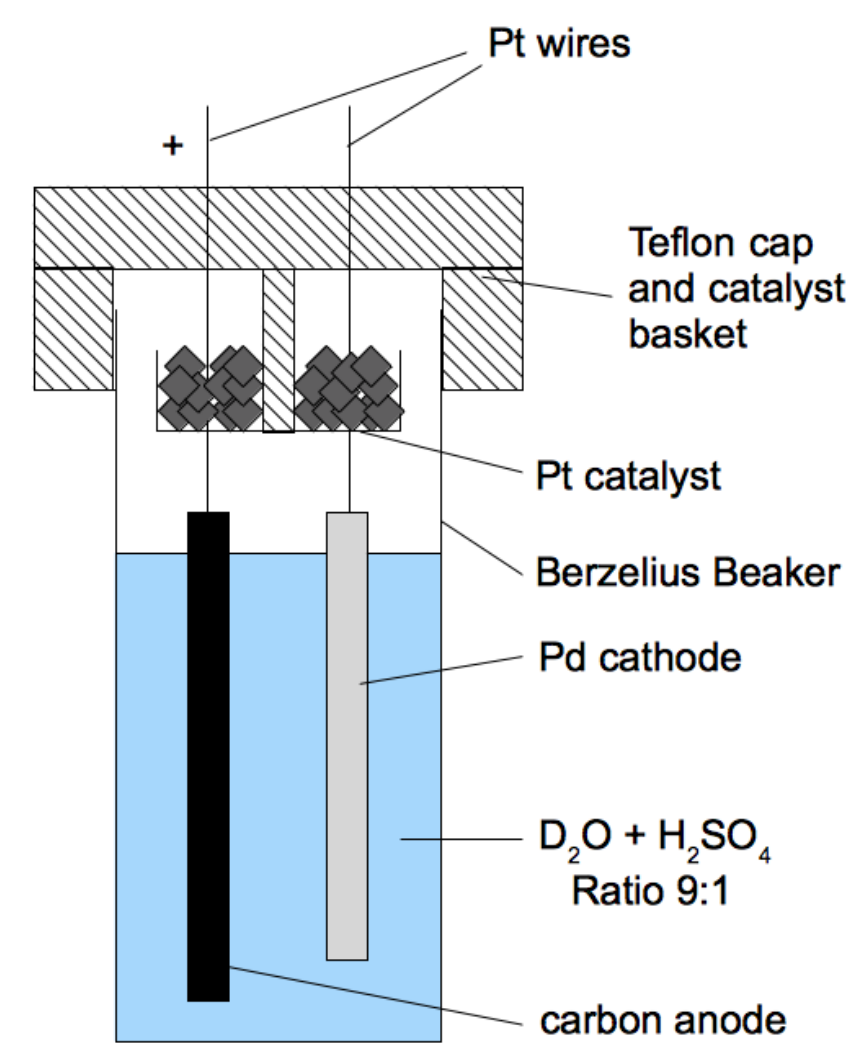

Figure 11: Schematic of the cell showing the main parts constituting the apparatus.

\section{b) Preparation of the electrodes}

The cathodes is a cold rolled foil of palladium cut from an original sheet of $100 \times 100 \times 5 \mathrm{~mm}$, that is reduced from 0.5 to $0.25 \mathrm{~mm}$ thickness in two passes. Before cold rolling the cut piece is sonicated in deionized water during $200 \mathrm{~s}$. After cold rolling, its dimensions are $72 \mathrm{~mm}$ long for $8 \mathrm{~mm}$ wide. This scientific grade metal is provided by the supplier Alpha Aesar ( $\mathrm{Pd}$ foil $0.5 \mathrm{~mm}$ Stock \#11514). The composition is $99.9 \%$ of palladium out of organic element. The trace elemental certificate is given in the annex.

The anode is a carbon electrode provided by the physics department laboratory supply 
stock. It is composed of $99.9 \%$ of carbon graphite and is commonly used during undergraduate lab program at PSU physics department for electrolysis.

c) Electrical energy input

The electrical output is monitored every $30 \mathrm{~min}$. The initial values are $4.0 \mathrm{~V}$ and $3.0 \mathrm{~A}$ (HP 6264B DC power supply). The corresponding current density on the surface of the cathode is close to $200 \mathrm{~mA} / \mathrm{cm} 2$. This value is not exact for a physical reason. The distance between the two electrodes can vary as the cathode bends during creation of the hydrides between the palladium metal and the deuterium on its surface. In fact, when the deuterium changes to deuteron and drops its electron, the loading induces a surface stress and changes the shape of the palladium. This phenomenon is not completely understood by the scientific community but is highly reproducible $[4,6]$.

\subsection{First experiment}

In the first experiment the size of the carbon anode was $5 \mathrm{~mm}$ in diameter and sustained by a clamp made in copper and provided by the physics laboratory stock. The electrolyte is prepared with $126 \mathrm{~mL}$ of $\mathrm{D}_{2} \mathrm{O}$ for a total of $150 \mathrm{~mL}$ of solution. Therefore the ratio of this solution is $6.7: 1$ of deuterium oxide per volume. The mass of sulfuric acid measured is $38.22 \mathrm{~g}$. The experiment is run for half an hour under the conditions described before. After this period of time, we noticed the dissolution of the clamp into the electrolyte that deposited on the surface of the cathode. This deposition is due to the positive potential of the copper in solution attracted by the negative charge of the potential into the cell. Following the advisor's advice the experiment is stopped. 
This mistake showed a very important aspect of electochemistery: everything located in the cell confinement will react during the electrolysis. In this case, the input current increased the temperature of the electrolyte. The evaporation condensed on the copper clamp and reduced it. This brought copper particle into the electrolyte. At this point the experiment has been contaminated at such a high level and cannot be run anymore. Unfortunately the duration is obviously too short to induce any significant loading of deuterium. However, the anode showed important degradations created during the short duration of this electrolysis.

\subsection{Second experiment}

Taking in consideration the failure of the first experiment, three modifications are made on the anode. The diameter of the anode is increased to $10 \mathrm{~mm}$ and the concentration of sulfuric acid is reduced to a ratio of $9: 1$ in order to reduce the chemical effect of acid on the dislocation of the anode. The platinum wire is bent around the top of the anode instead of using the copper clamp. The conduction of this assembly is tested with an Ohm-meter. The meter reported a value in magnitude of a tenth of micro-Ohms confirming of a very good conduction.

Facing the doubt of the importance of the missing platinum in the component necessary to create energetic phenomenon, the cathode has been covered with a thin layer of platinum with the help of a sputter coater (Plasma science $\mathrm{CrC} 100$ ). The potential applied at the beginning is $1.0 \mathrm{kV}$ with a pressure of $1.0 \mathrm{mTorr}$ in an argon atmosphere, after the plasma started and stabilized the potential was $0.8 \mathrm{kV}$ and the density was $100 \mathrm{mTorr}$. The detector

gave a value of $9.0 \AA$ of deposited platinum that is much depreciated because the operator confirmed of a thickness comprised between 5 to $10 \mathrm{~nm}$. Unfortunately, the no AFM 
microscope was available at that time.

Each cell part is cleaned with tap water in an ultrasonic bath for half an hour. Another cathode is attached to the platinum wire and a new electrolyte is prepared. The electrolyte is composed of $126 \mathrm{~mL}$ of $\mathrm{D}_{2} \mathrm{O}$ and the total volume og the electrolyte is $150 \mathrm{~mL}$. The experiment is started at the end of the day and gives the following measurements. $4.92 \mathrm{~g}$ of catalyst are placed at the top of the cell. 


\section{Measurements}

The measurements made during this experiment were the electrical potential and the current applied to the cell and the temperature at the bottom of the beaker. The following table shows these values. The experiment is run during a cumulated time of 300 minutes with two interruptions, the first one happened because of nighttime and the other one because the graphite anode disintegrated into the electrolyte after 450 minutes. This disintegration was caused by the coupled effect of the sulfuric acid into the electrolytic solution and the effect of the current density on the structure of this graphitic anode.

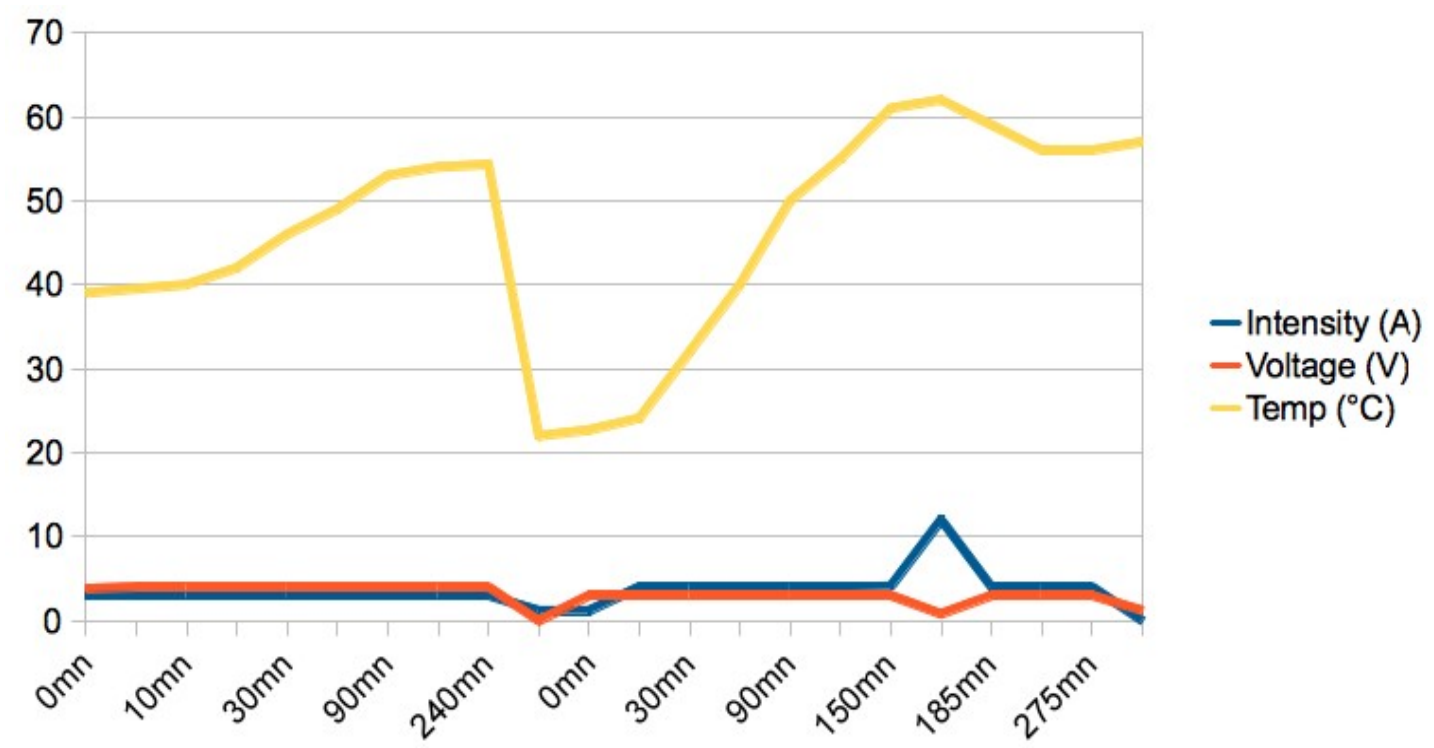

Figure 12: Experimental measurements of experiment \#2. We can notice two main variations. The first one is because of the night and the other one because of the dislocation of the anode in the electrolyte. 


\begin{tabular}{|c|c|c|c|c|}
\hline & Time (mn) & Intensity (A) & Voltage (V) & Temperature $\left({ }^{\circ} \mathrm{C}\right)$ \\
\hline t0 & $10 / 11 / 10,7 \mathrm{pm}$ & 3 & 3.8 & 39 \\
\hline $\mathrm{t} 1$ & 5 & 3 & 4 & 39.5 \\
\hline $\mathrm{t} 2$ & 10 & 3 & 4 & 40 \\
\hline $\mathrm{t} 3$ & 20 & 3 & 4 & 42 \\
\hline $\mathrm{t} 4$ & 30 & 3 & 4 & 46 \\
\hline $\mathrm{t} 5$ & 60 & 3 & 4 & 49 \\
\hline t6 & 90 & 3 & 4 & 53 \\
\hline $\mathrm{t} 7$ & 120 & 3 & 4 & 54 \\
\hline $\mathrm{t} 8$ & 240 & 3 & 4 & 54.3 \\
\hline t9 & NIGHT & 1.2 & 0 & 22 \\
\hline $\mathrm{t} 10$ & $10 / 12 / 10,1 \mathrm{pm}$ & 1.2 & 3 & 22.7 \\
\hline $\mathrm{t} 11$ & 5 & 4 & 3 & 24.1 \\
\hline $\mathrm{t} 12$ & 30 & 4 & 3 & 32 \\
\hline $\mathrm{t} 13$ & 60 & 4 & 3 & 40 \\
\hline $\mathrm{t} 14$ & 90 & 4 & 3 & 50 \\
\hline $\mathrm{t} 15$ & 120 & 4 & 3 & 55 \\
\hline $\mathrm{t} 16$ & 150 & 4.1 & 3 & 61 \\
\hline \multicolumn{5}{|c|}{ ANODE CHANGED BECAUSE IT DISSOLVED INTO THE ELECTROLITE } \\
\hline $\mathrm{t} 17$ & 155 & 12 & 0.8 & 62 \\
\hline $\mathrm{t} 18$ & 185 & 4 & 3 & 59 \\
\hline $\mathrm{t} 19$ & 245 & 4 & 3 & 56 \\
\hline $\mathrm{t} 20$ & 275 & 4 & 3 & 56 \\
\hline END & 275 & 0 & 1.2 & 57 \\
\hline
\end{tabular}

Table 1: Experimental measurement of experiment \#2

In the other experiments usually made in our laboratory, the average temperature is close to $90^{\circ} \mathrm{C}$, in this one the average temperature is $46^{\circ} \mathrm{C}$. This drop is attributable to the absence of the catalytic effect produced by the platinum anode and the nighttime stop.

After a cumulative time of 450 minutes, the carbon anode suffered the same effect as noticed in the previous experiment. It entirely dissolved into the electrolyte shaping a asymptotic contact between the level of the liquid and the bottom of the anode remaining 
attached to the platinum wire. This has an effect during the first five minutes when the energy is applied to the cell. Because the power supply is made to deliver a constant current to the cell in normal conditions, when conductivity reduces the power supply has to set the current a higher value to reestablish the conduction through the air. But when the conduction is reestablished the current is set back to the original value. This induced periodic variations and created a drastic increase of the energy injected into the cell and resulted an increased temperature of the electrolyte.

In Figure 12, we can see the value of temperature is maximum when this problem occurred. However it is not the real value of the liquid because the thermocouple was placed behind the glass of the beaker. The measured value is probably deviated compared to the real one.

After five minutes when the cell was not under direct control, the power supply had been turned off and unwired. The head of the cell had been removed letting the cathode out of the electrolyte for few seconds. At that time the electrolyted evaporate quickly due to the temperature of the electrolyte and showed the surface facing the anode black and mate. The color and reflectivity of light is due to the electrodeposition of the carbon on the surface of palladium. We will see the effect of this phase during the study of the features.

As soon as the carbon rod has been replaced and checked, the power supply is turned back on and the experiment is run for 120 more minutes. After this duration the current has been stopped following a request of the advisor.

Then the electrode has been sonicated during 600 seconds in deionized water. After this step we were surprised to see large quantities of unknown gases coming out of the 
electrode. This was unexpected and we did not have the opportunity to analyze it with a gaseous phase mass spectrometer. It will be of interest to see if any tritium or helium has been released by the sample after this step. Then the sample has been let to dry out in ambient air.

The first aspect that was interesting is that if the side facing the anode shows a lot of features, the backside is completely unchanged and nothing was showing any alteration or changes. 


\section{Study of features on the surface of the electrode}

This is the most exciting part of the study that I have done during the two years of my Master's program. In order to put the size of the features we are studying in perspective, the following chapter is organized regarding the magnification and the size of the different features found on the electrode.

\subsection{Characterization of macro-features}

Some features are sufficiently big enough to be seen with the naked eye or at low magnification using a light microscope which gives some clues about the phenomenon we are studying. In the following picture given in Figure 13, we can see a variation of height on the surface of the cathode. This proves that a large scale phenomenon occurred with enough energy to change the topography of the palladium. Almost the entire surface of the cathode was covered with the same features.

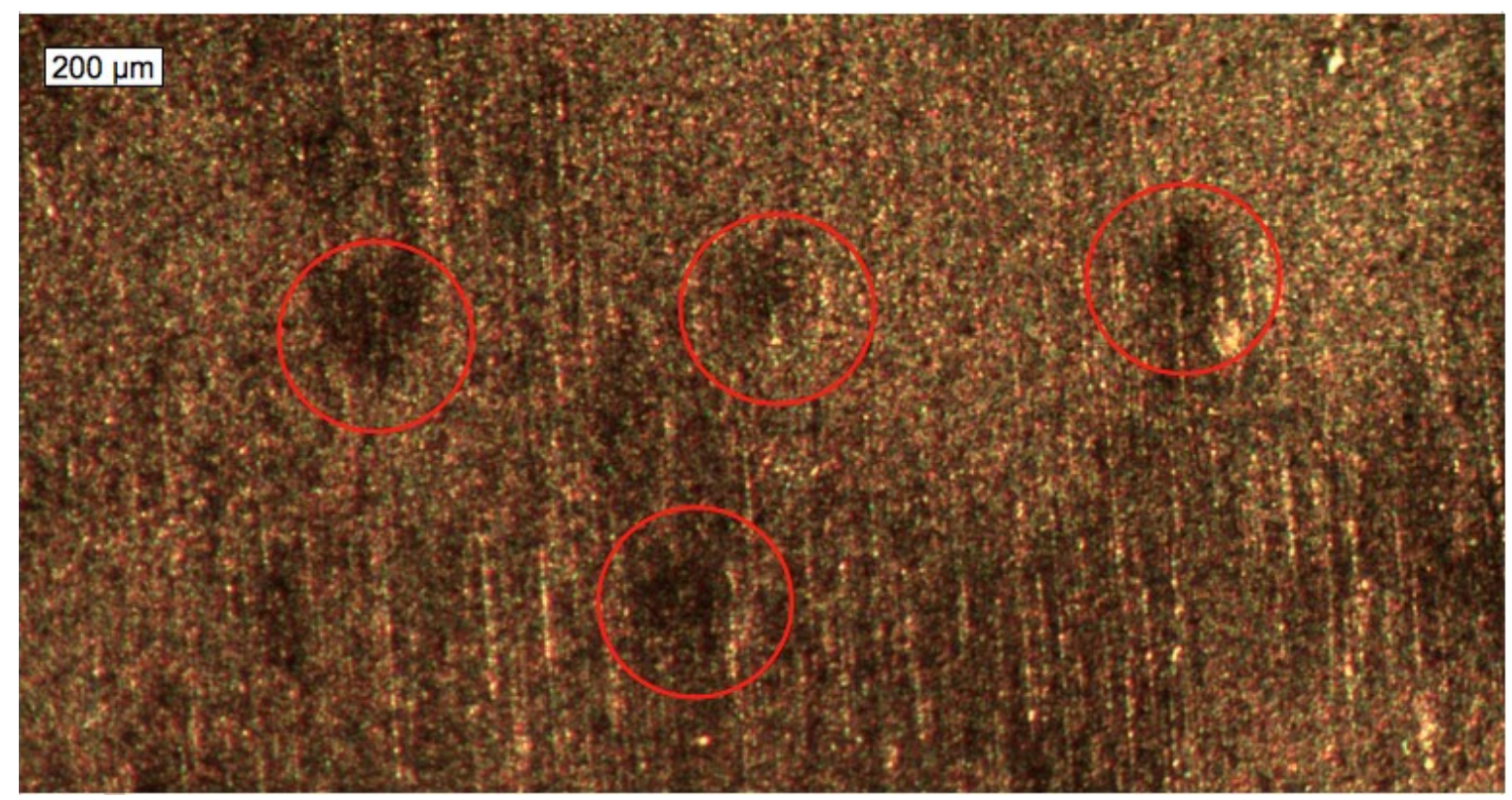

Figure 13: Light microscope picture of changes in topography of the cathode 
The batch of picture given in Figure 14 shows that same kind of features is present all over the surface of the cathode facing the carbon anode. The size of this topological phenomenon was approximatively the same everywhere on the cathode.

As we can see, the topography of the sample's surface shows circular features on it. Unfortunately, the microscope was not setup entirely right and it is not possible to give the exact scale of them from these pictures. However, as showed in Figure 13 these features are approximately $150 \mu \mathrm{m}$ diameter.

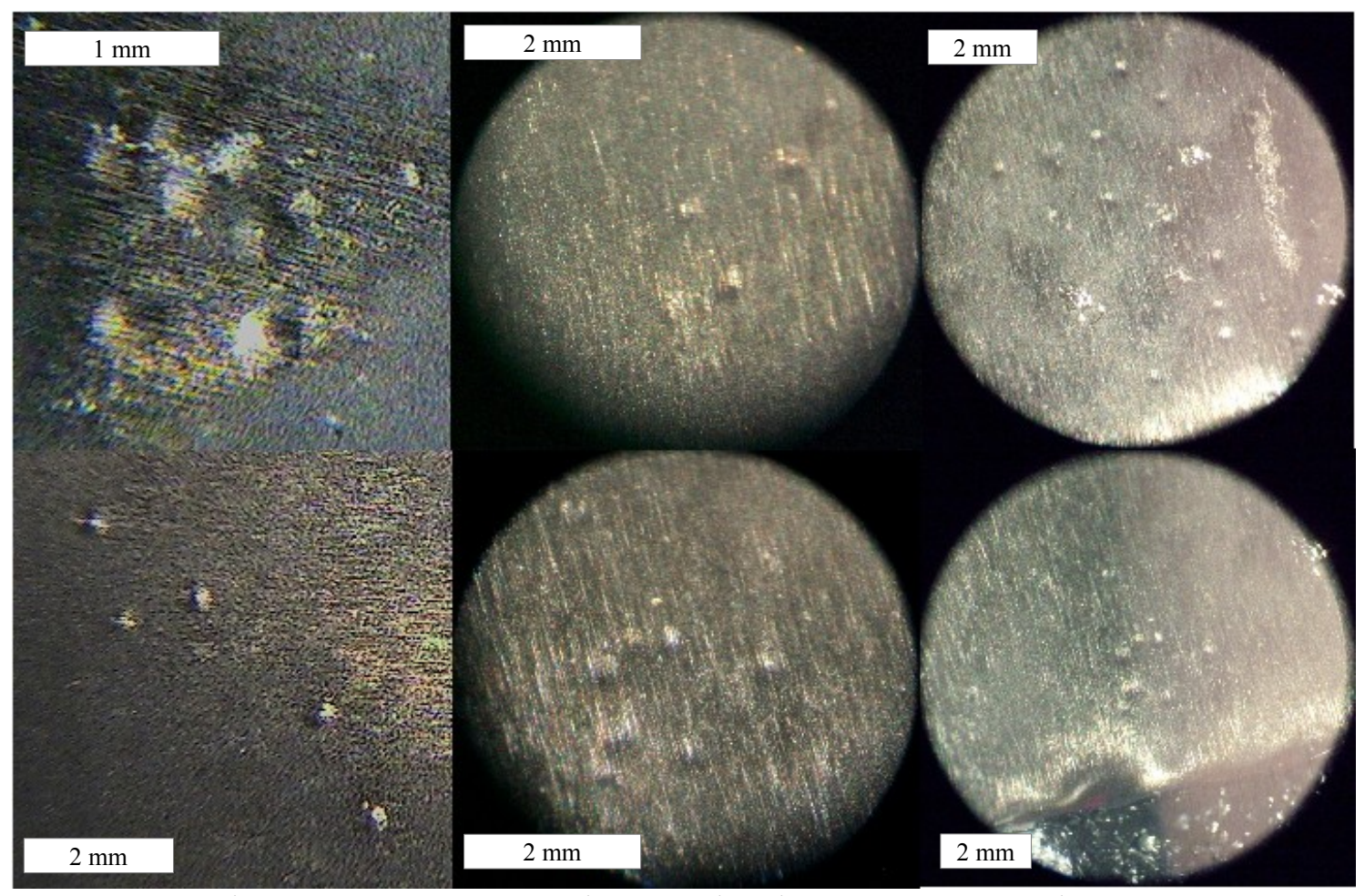

Figure 14: Light microscope images showing the change in topography

In Figure 14, the two pictures on the first row are not at the magnification but the light is coming from the same direction (from the right) and the same light microscope has been 
used to take them. One of the most interesting aspects of these features is the depth of these circular variation in topography. In the upper picture, the right part of each feature is brighter than the left part. This shows that the feature is convex. In the lower picture the left part of the feature is brighter than the right part. This shows that the feature is concave.

Hence, we showed these features can be convex or concave. The bumped surface can be interpreted as an energy release that changed the shape of the surface originally flat of the palladium electrode, but the pits did not find a clear explanation. More investigation should be done on these features, especially with a deep FIB milling technique, similar to that used in TEM sample preparation. This technique would be helpful defining the depth where the reaction occurred, the nature of the reaction and eventually show precise elemental analysis at this location.

\subsection{Characterization of micro-features}

Compared to the original experimental setup, the first aspect we can notice is the general flatness of the surface. This absence of platinum features will improve greatly the precision of measurement during depth profiling.

SEM images show us a different size of phenomenon that occurred on the surface of the cathode. After electrolysis the surface was covered by very small features, $4 \mu \mathrm{m}$ to $7 \mu \mathrm{m}$ in diameter. They have approximately the same size as previously found features at the bottom of the platinum "volcanoes". 


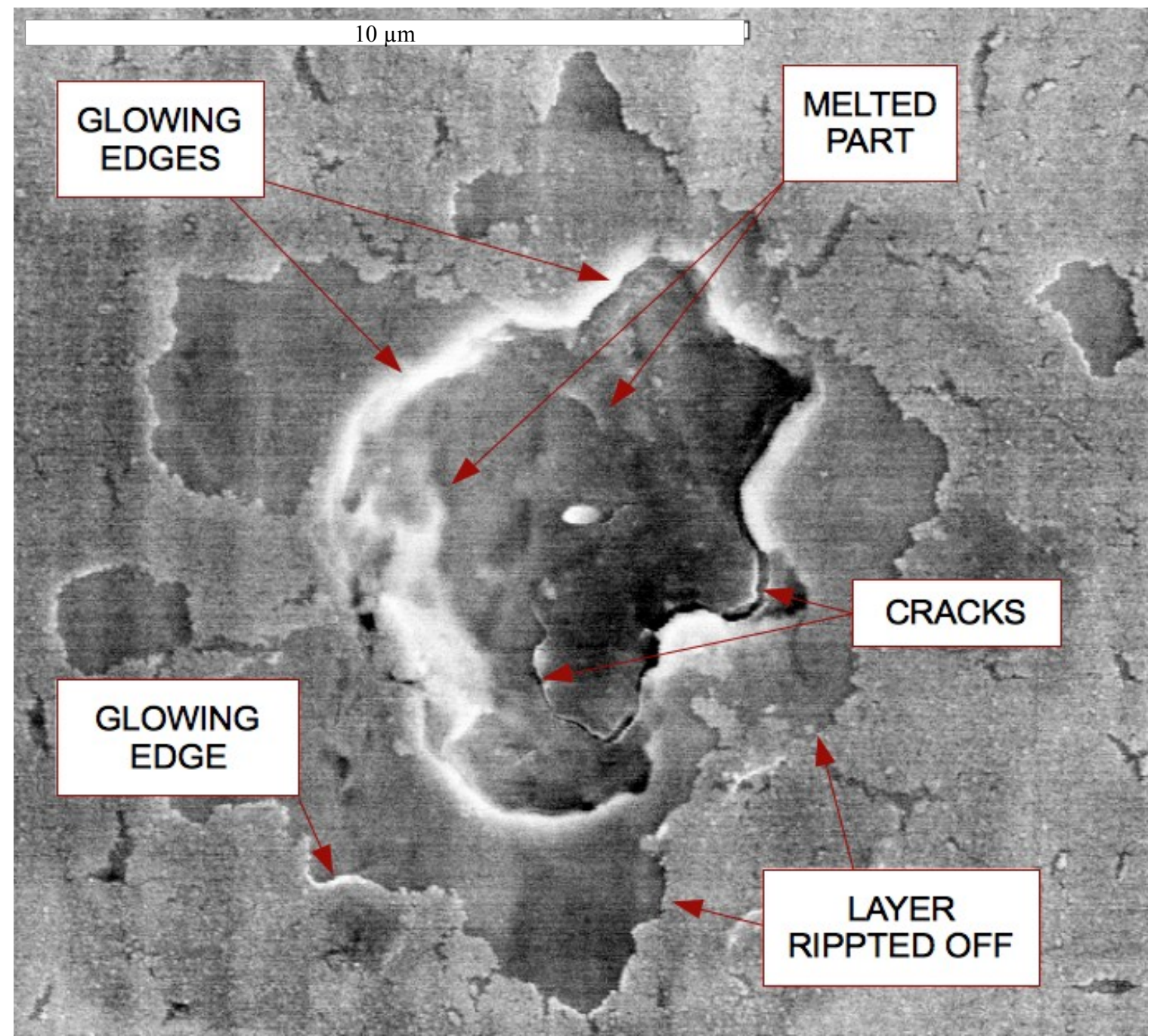

Figure 15: SEM picture of a hole on the surface of the cathode

Figure 15 shows a hole on the surface of the cathode. Because the SEM is not able to define the topography easily, we have to look at the glowing borders of the hole as an increase of the secondary electron yield inducing this variation of contrast. It is testifying a very sharp edges around the hole where secondary electrons escape from underneath and have to go through again because they are attracted by the bias of the detector.

At the bottom to the hole we can see a waving of the surface suggesting liquefaction and resolidification of material. We can also see cracks on the lower right part of the image. 
All around the hole the platinum layer has been ripped off the surface of the sample. In the same way as the glowing edge we can see an edge of the platinum glowing due to excessive secondary ion yield. The sputtering did not create formation of an alloy between the surface grains of the palladium substrate and the plasma of platinum. Therefore it was easy for the platinum to be taken off the surface.

No significant change in the substrate material composition has been found, it would be of interest to filter the electrolyte, separate the particles ejected from the hole an do elemental analysis.

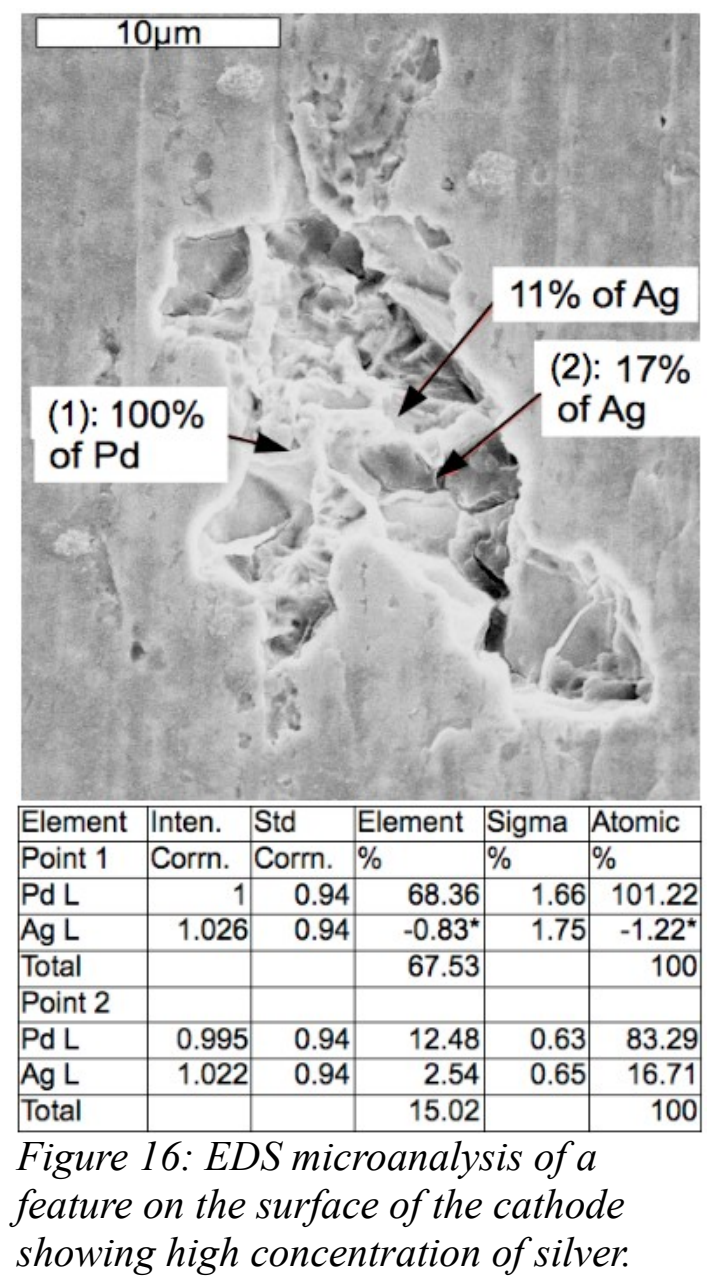


Figure 16 shows an interesting feature in terms of elemental microanalysis. The EDS is calibrated, following the standard, with a piece of copper and a beam at $20 \mathrm{keV}$, just before the analysis. This feature shows an important concentration of silver in the sample. This silver has been detected in two locations pointed in the picture. Two results of microanalysis are presented on the right side where the silver is completely absent and the silver showed its maximum value. However, because the flatness of the surface has an important role in this measurement, the reliability of these results is not entirely proven, as showed by the sum of the elemental results showed for point 2.

Around the previous feature we can see some very small fluffy dots. They will be studied in the following pages. Their composition always showed presence of copper (between 5 and $8 \%$ ) inside the feature but never on the rest of the surface, and their composition can be compared easily with the EDS and the SIMS because they can be found everywhere.

On the EDS analysis given in Figure 17, we can see the main component of these features is copper. Because the beam was set to $20 \mathrm{keV}$, the volume impacted that generated $\mathrm{x}$-rays included the palladium and the platinum of the surrounding.

Some trace elements are present in the spectrum. Iron and gallium are given in the composition of this feature. If the gallium is known to be from the ion gun source, the iron has a less obvious origin. We can imagine the chamber of the SIMS would have contaminated the sample because of its high concentration of iron. 

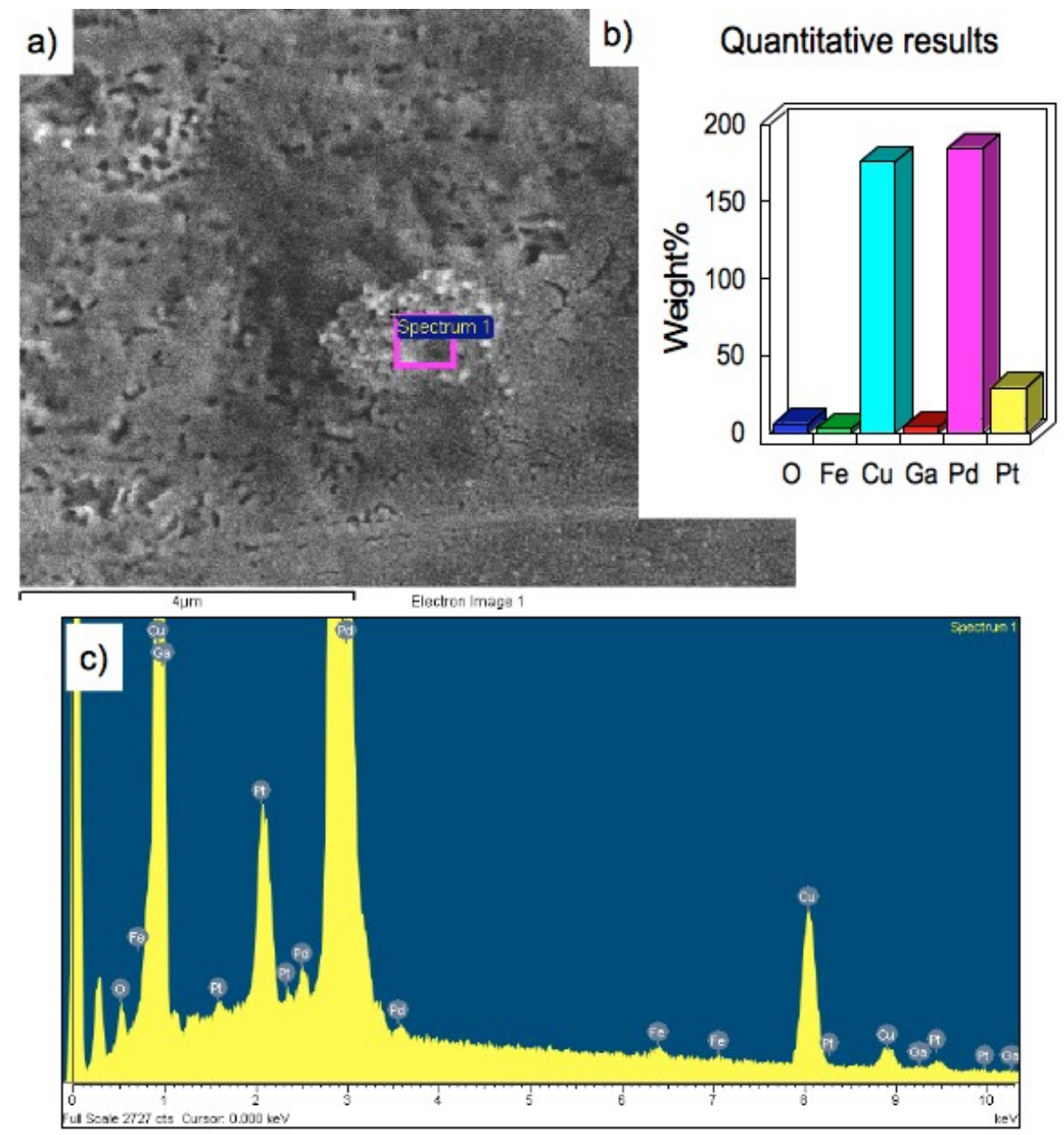

Figure 17: EDS microanalysis of the copper dots. a) Image if rhe location the spectrum is originated from. b) Elemental results of the microanalysis. c) Spectrum of the location analyzed.

Using the high resolution imaging system of the SEM FEI Sirion we are able to give details of one of these copper features.

The picture given in Figure 18 shows the shape of these features. It also shows some cracks on the right side and the same aspect of a platinum layer ripped of all around the copper dot. 


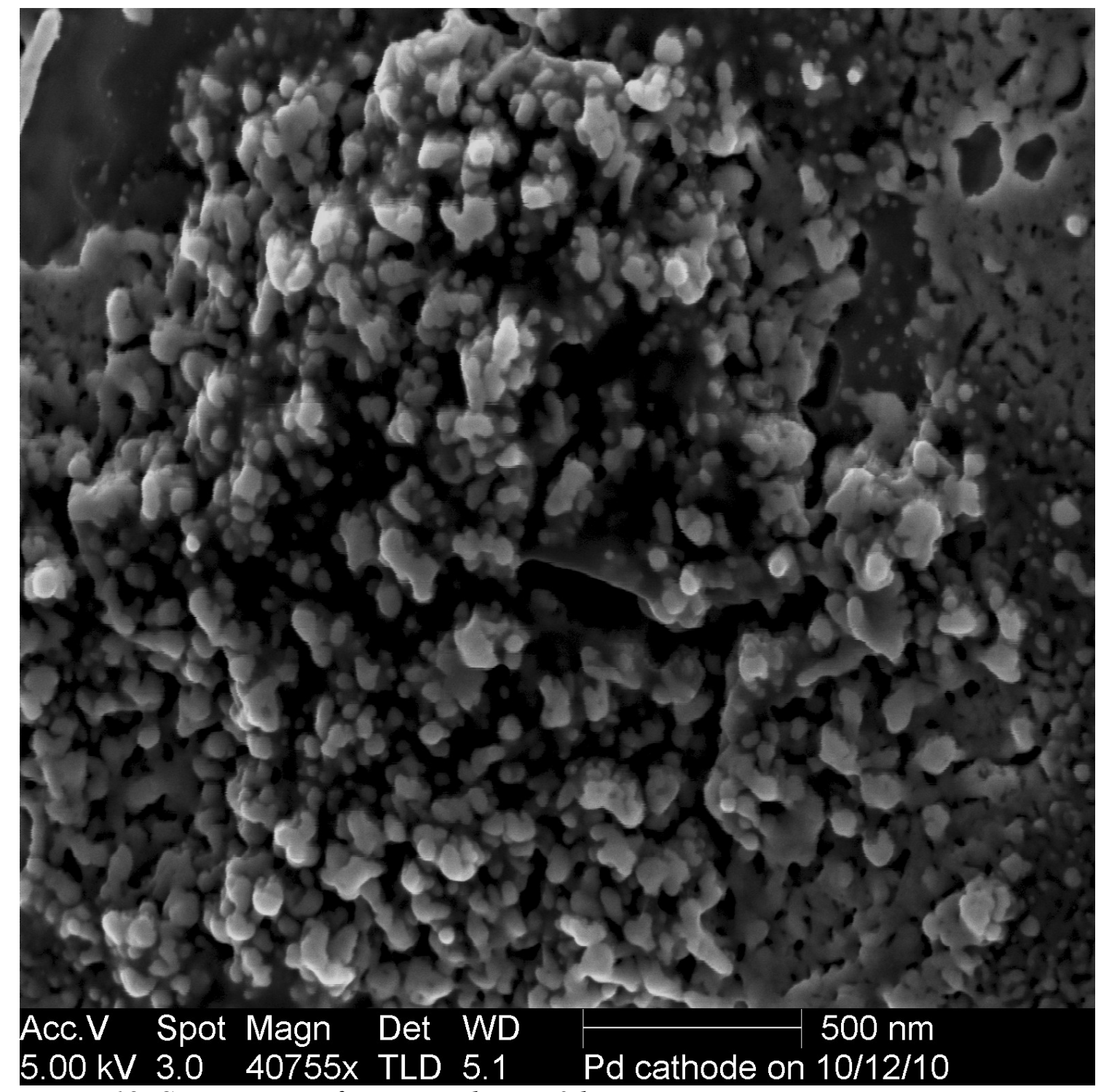

Figure 18: SEM picture of a copper dot at $40 \mathrm{kx}$.

In order to determine if these features were coming from contamination or were generated by the experiment, the SIMS had to define the isotopic composition of these dots. If the value fits with the natural abundance, the doubt about the origin of this element will be determined. 


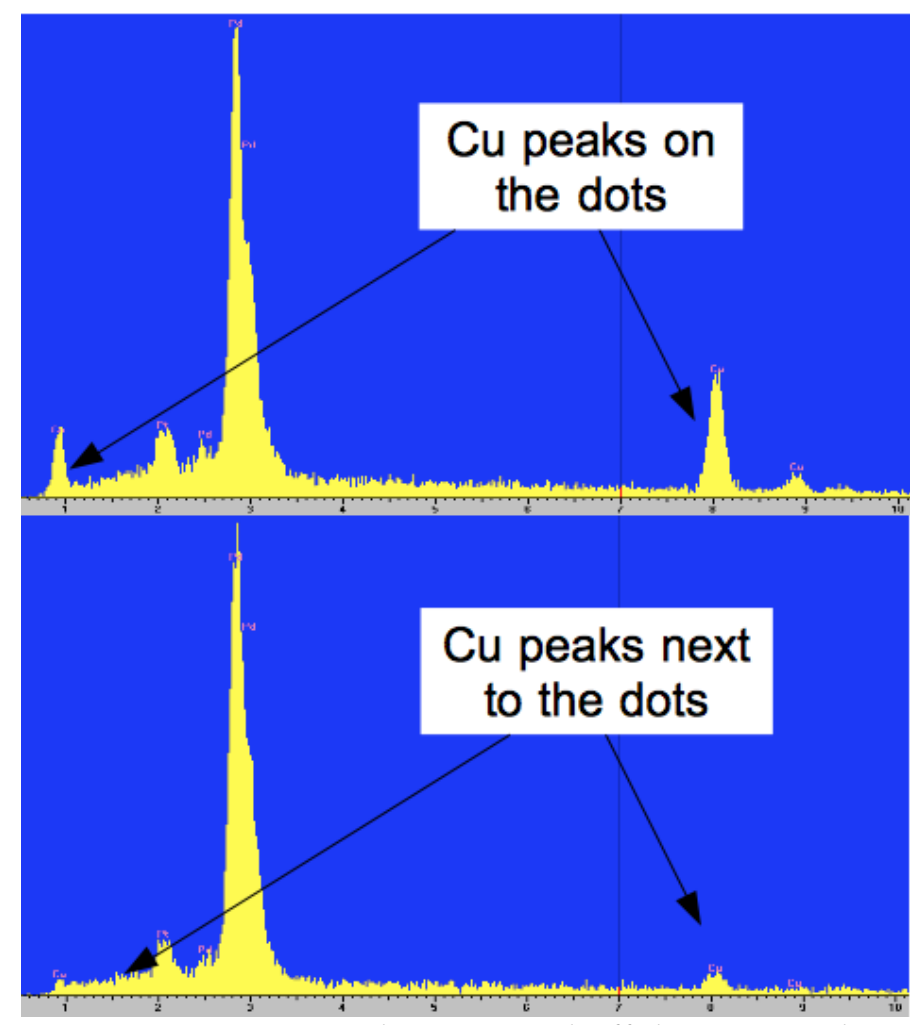

Figure 19: Microanalysis on and off the copper dots. On the upper spectrum the copper is present when the electron beam is pointing directly to the feature whereas it reduces drastically next to it.

EDS microanalysis of one of these copper features gave a clear signal of the presence of copper. For two spectra shown in Figure 19, one is taken on and the other is taken off these features, the copper signal disappears almost completely.

The secondary ion mass spectrometer gives direct value of isotopic concentration of these features. $69 \%$ of the analyzed copper was made of ${ }^{63} \mathrm{Cu}$ and $31 \%$ of ${ }^{65} \mathrm{Cu}$. The natural abundance of copper is $70 \%$ for ${ }^{63} \mathrm{Cu}$ and $30 \%$ for ${ }^{65} \mathrm{Cu}$.

This SIMS analysis gives values close to the natural abundance, bringing discredit to the potentially created element. This contamination is probably coming from the previous experiment where the copper clamp has been dissolved into the electrolyte. Therefore 
multiple sonication during longer period of time is necessary. However, the shape of these features brings an interesting aspect that would be of interest to investigate furthermore.

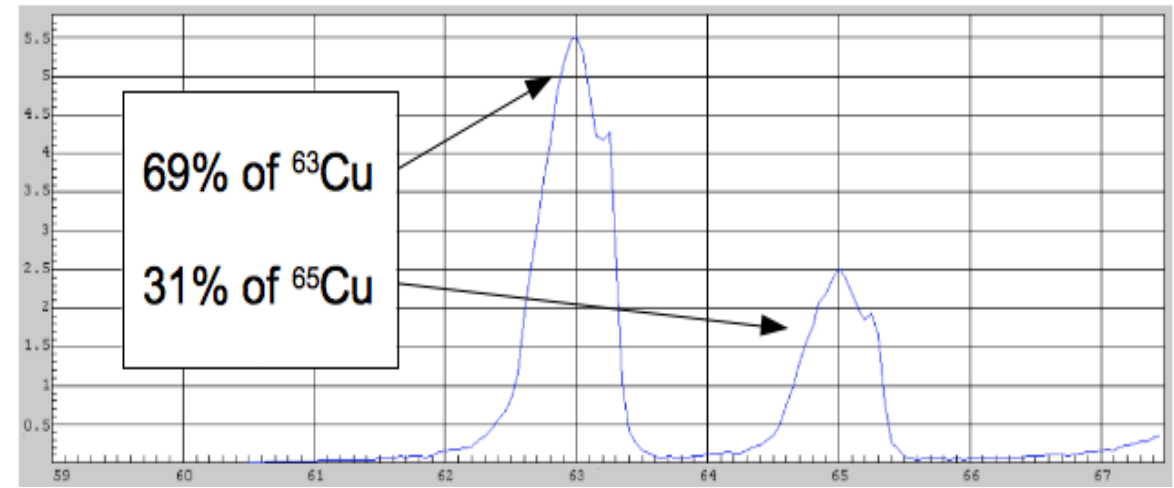

Figure 20: SIMS analysis of a copper dot. The amount of $\mathrm{Cu}(63)$ is $69 \%$ and the $\mathrm{Cu}(65)$ is $31 \%$.

This analysis showed the main complementary aspect these two mass spectrometry devices can efficiently share to give more clues about what is happening during these experiments.

Figure 21 shows the carbon left on the surface of the electrode. This carbon covers less than $10 \%$ of the surface and cannot be removed by sonication. This carbon shows a specific pattern of a puzzle with a variation of contrast at the center of each piece. Because the cathode was very hot when the anode dissolved in the electrolyte, when it has been taken out of the liquid it dried very fast and cracked at the same time as it hardened. This aspect can be interpreted as a vitrification of the carbon deposited on the surface of the cathode. 


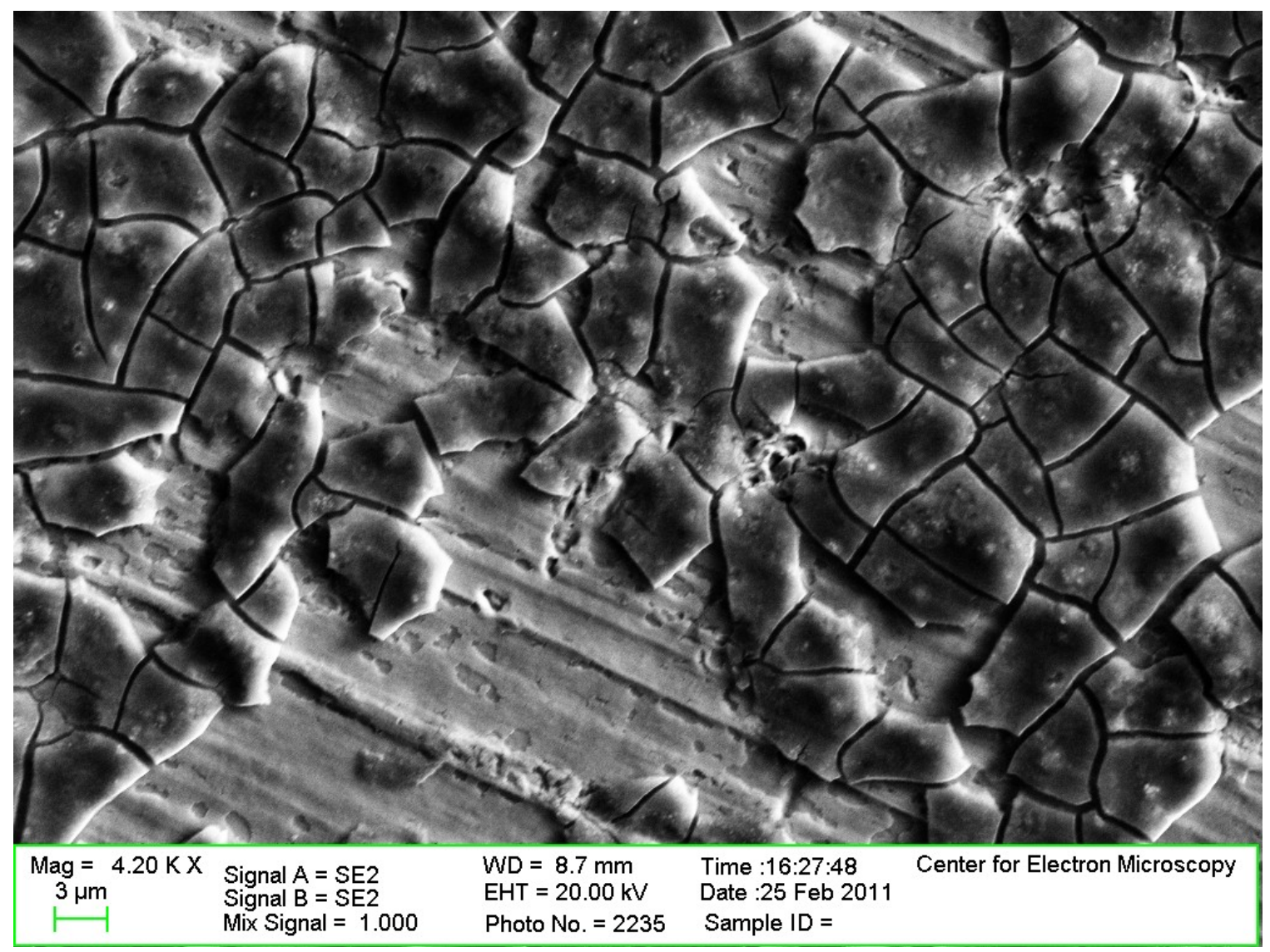

Figure 21: SEM picture of the vitrified carbon on the surface of the cathode at $4,2 \mathrm{kx}$. We can notice the change in contract at the center of each puzzle part.

This closes the study made with the SEM and the EDS microanalysis tools. To briefly summarize, we were able to define the composition of macro-features showing very energetic phenomenon occurring all over the surface. Some micro-features shaped like holes, others showing variation in elemental composition. Also very small features made of copper coming from the previous experiment by contamination. Finally some carbon coming from the anode and solidified has been studied. 


\section{Palladium Isotopic measurements}

The isotopic measurements have several requirements in order to prove reliability and reproducibility during the acquisition. For example, it is essential to consider the intrinsic drift of the measurement device during the acquisition. Therefore, it is necessary to prepare the sample with the experimental electrode next to a piece of the original palladium. This allows us to make comparative measurements between the sample and the abundance originated from the same piece of palladium. It is also necessary to alternate the measurements to reduce the measurement drift. This drift changes the intensity, the ratio signal over noise and improves greatly the reproducibility.

\subsection{Evaluation of the milling rate produced by the ion gun}

This step involved two different tools, the focused ion beam (FIB) is used to mill a depth profile pattern on the surface of the sample and an atomic force microscope (AFM) is used to verify the depth of the milled. The SEM is also used to observe precisely the topography of the pattern.

Figure 22 shows a test of milling with a high energy gallium beam. The acceleration current used was $5.0 \mu \mathrm{A}$ and it took two hours to mill through $20 \mu \mathrm{m}$ depth. We can see how the surface has been impacted by the process. This shows how palladium hardness was reacting and how much this current was too intense. At the top of the pattern we can see how the gallium did not break into the grain metal and implanted at the grain join.

The lower part of the pattern shows a place where an electro-deposited platinum was present. The beam barely removed the platinum, in fact the beam ions were trapped by the 
platinum and then consolidated the reshaped object. We can also notice how the surrounding of the pattern is covered by redeposited gallium.

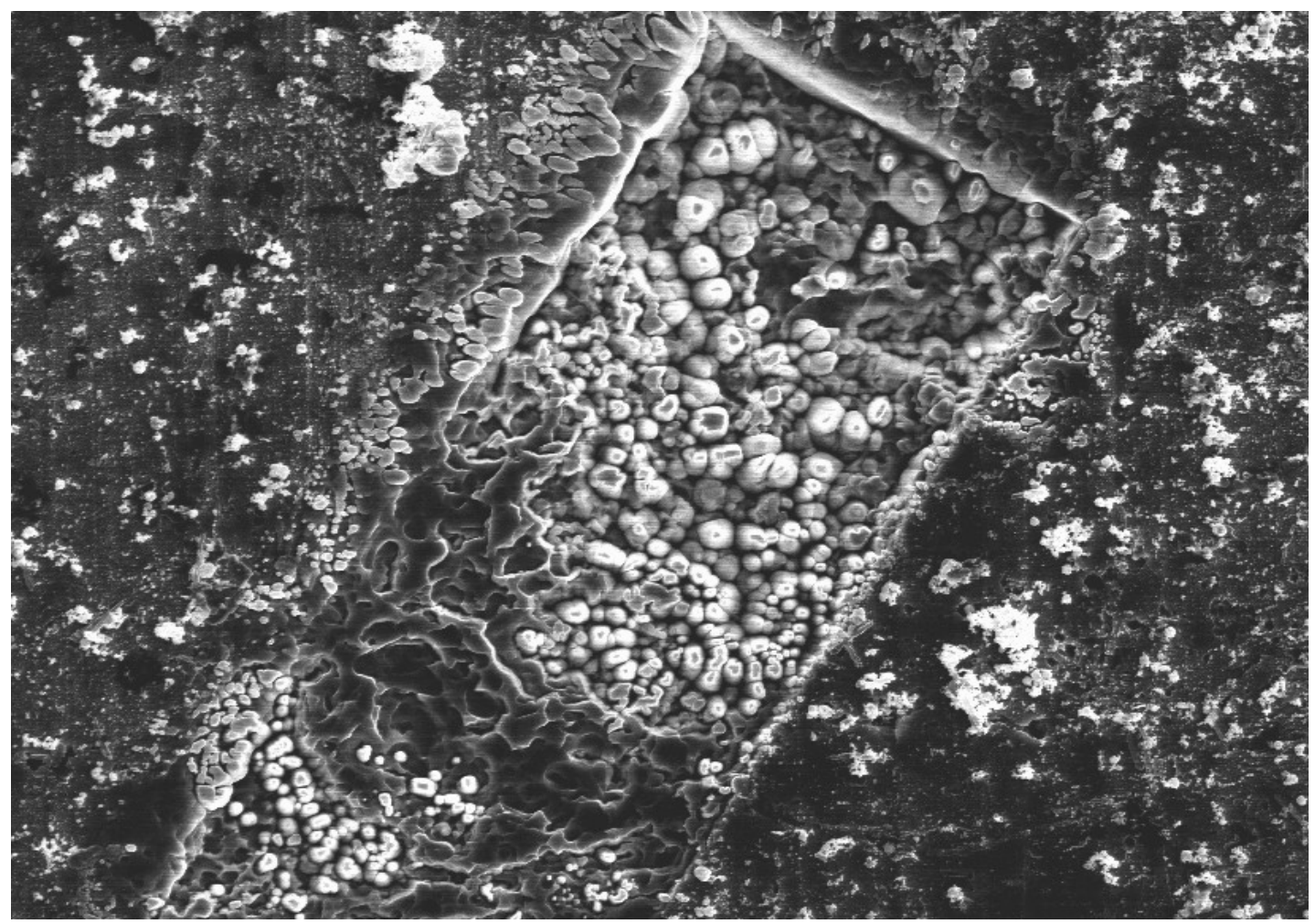

FiFigure 23: SEM picture of a milling pattern made with high energy ion beam. The papattern is $50 \mu \mathrm{m}$ in width.

Figure 23 shows an analysis made of another milling and measured with the AFM. This milling has been made with an acceleration current of $500 \mathrm{pA}$. After numerous tests this value of beam intensity gives a good quality of milling, a good secondary ion generation rate, and an acceptable duration of milling. 

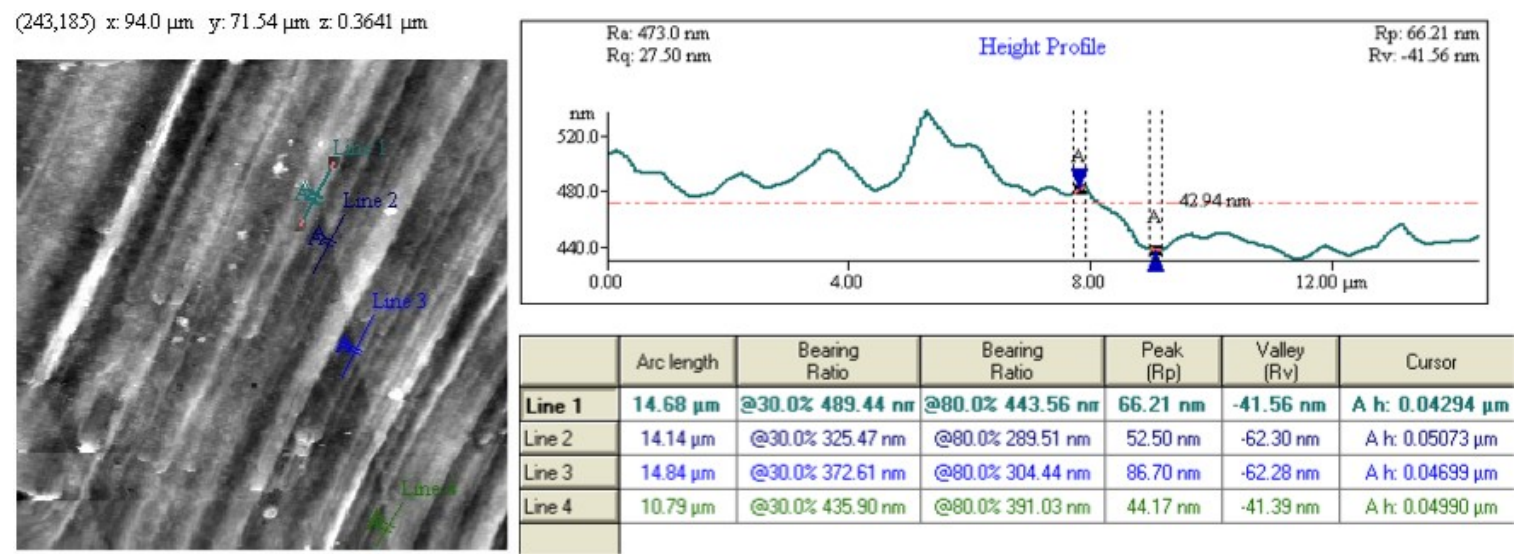

Figure 24: AFM analysis of an ion milling made at $500 \mathrm{pA}$. On the left picture we see the milled surface. On the upper right, we see the profile of the top line of the picture. On the last frame we see the results of the step analyzed giving a value close to $50 \mathrm{~nm}$.

\subsection{Incompatibility of the sputtered platinum}

This was the most frustrating step of my research. After the intense characterization made with the SEM/EDS on the sample prepared and loaded with the carbon anode, the beginning of the SIMS measurement proved that no spectrum measurement was possible with this sample. The reason for this is coming from the plasma deposited platinum all over the surface of the electrode. Even if this layer of platinum is fragile and not intimately assembled (alloyed) with the palladium substrate, the unexpected effect brought by the gallium ion beam put a sudden end to the investigation on this sample. The explanation is because the beam is barely able to remove the platinum, the implantation is the only possibility allowed for the platinum.

Hence, the gallium slowly builds on the surface of the electrode with no other signal sent to the mass spectrometer. This observation was frustrating but the only solution left was to study a sample that has been loaded recently because storage causes a build up of 
contamination and dust on the surface changing the spectrometric results. The consequences are multiple. The signal to noise ratio skyrocketed because this sample is partly covered with platinum particles from the electrodeposition reducing the palladium signal. The study of the isotopic variation along the depth is not possible anymore because the sample cannot be milled evenly and the precision in the depth of milling is greatly changed. However the palladium used for this experiment is coming from the same stock as the one used previously.

\subsection{Elemental analysis}

The first interesting aspect of these measurements is to define by another means of composition of the sample. The spectra in Figure 25 have been done through measurement of a full length spectrum on sample loaded in June 2010 and briefly studied in Chapter 3.4.

\section{Full Spectrum for the Control Cell}

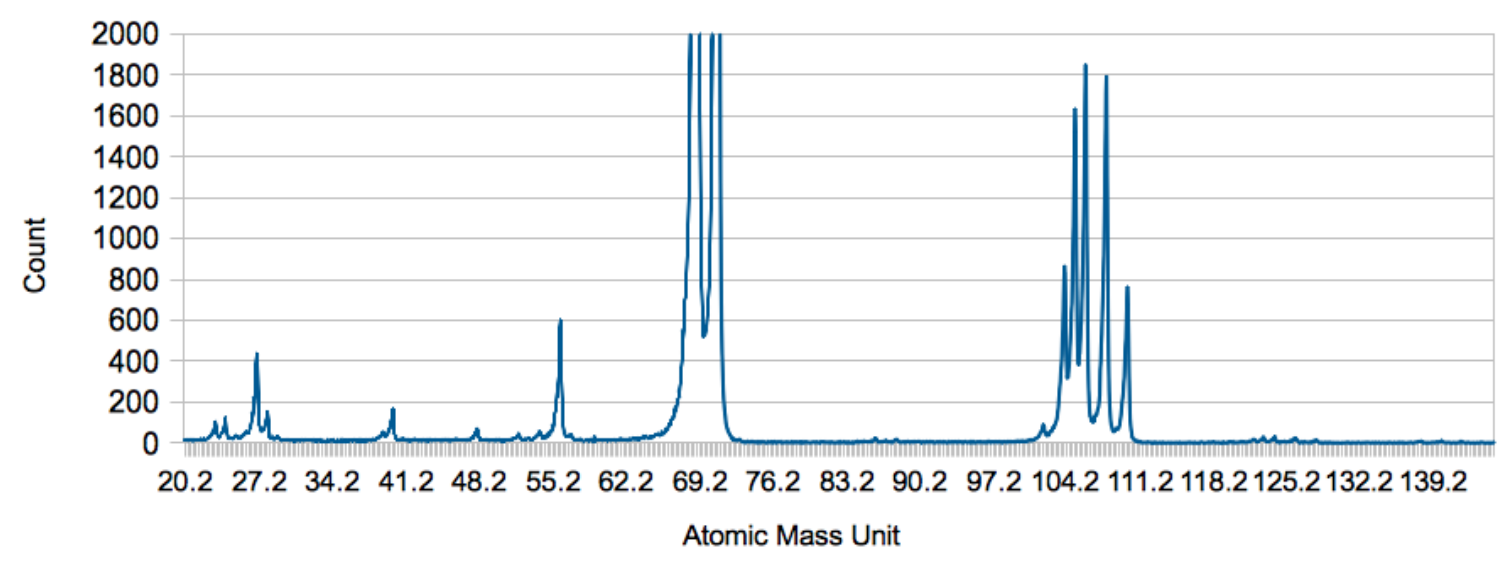

Figure 25: SIMS Spectrum of the original palladium. The main peaks at the center are the gallium source. On the left the palladium shows its 6 isotopes. Are also present Fe, Al and small amounts of Ti and $M g$. 
This spectrum shows the main components of the original palladium used for both experiments. The spectrum has been cut on each side because no significant signals were detected. Even if quantitative elemental analysis are possible with a SIMS for a single element, it is not possible to do this across the entire spectrum. The detection ratio of this type of tool reduces with the increase of secondary ion mass [9], hence the intensity of each peak should be considered differently regarding their mass. The light elements from 20 AMU to 70 AMU are easy to collect so small quantity are detected easily.

We can see how the original palladium is composed of some trace element that does not always appear in the trace elemental analysis given by the supplier present in annexe. Titanium and magnesium are detected where they should not be. Aluminum and iron are however detected by the SIMS and present in the trace elemental analysis. Se can also notice some $\mathrm{Pd}+\mathrm{O}$ dimers showing small signal around 125 AMU.

\section{Full Spectrum for the Experimental Cell}

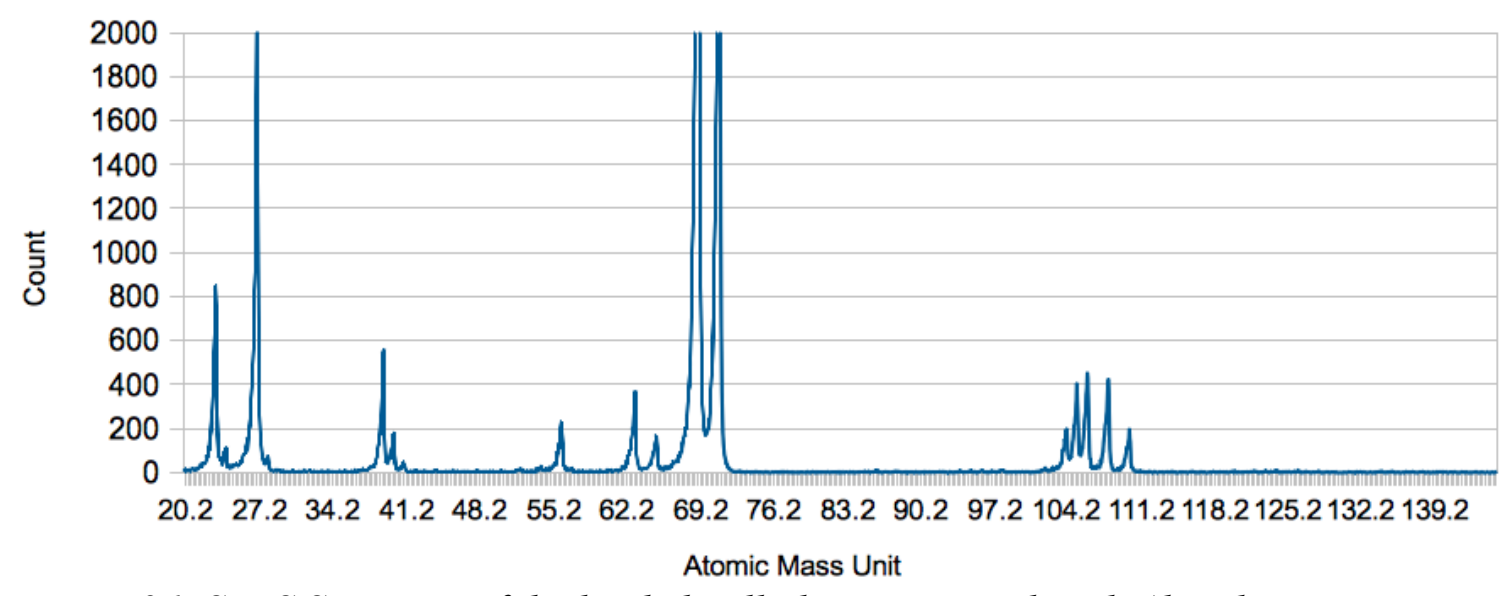

Figure 26: SIMS Spectrum of the loaded palladium. Fe is reduced, Al and Mg are enhanced. K peak is stronger. Zn is new. 
Figure 25 shows the spectrum taken on the loaded cathode. We can see how the palladium signal is reduced by comparing their height on the two spectra. Elements like magnesium, potassium and aluminum are enhanced whereas iron is reduced. Potassium is interesting because it seems to show three isotopes with a decreasing concentration. This is not following the values of the natural abundance given by the standards $\left({ }^{39} \mathrm{~K}: 93.26 \%,{ }^{40} \mathrm{~K}\right.$ : $\left.0.01 \%,{ }^{41} \mathrm{~K}: 6.73 \%\right)$. Finally the zinc is new and did not find yet any origin, its isotopic composition is not following the natural abundance as well because on peak is missing $\left({ }^{64} \mathrm{Zn}\right.$ : $\left.48.63 \%,{ }^{66} \mathrm{Zn}: 27.9 \%,{ }^{67} \mathrm{Zn}: 4.10 \%,{ }^{68} \mathrm{Zn}: 18.75 \%,{ }^{70} \mathrm{Zn}: 0.62 \%\right)$.

\subsection{Isotopic variation of palladium}

As introduced in the previous chapters the consequences of the platinum plasma coating had unexpected effect on the SIMS measurements and impacted the original investigation objectives of this research. However, using the sample studied in chapter 3.5 which was loaded recently with the same deuterium and coming from the same stock, we are studying the variation of palladium isotopes on the first $50 \mathrm{~nm}$ because the acceleration current is again set at $500 \mathrm{pA}$. Ten measurements are made alternatively on the control Pd and the loaded metal with a unitary duration of $240 \mathrm{~s}$.

The calculation of the isotopic concentration is inspired from the SIMS manual provided by FEI [11]. The method described in this documentation calculates the maximum value of the peak, then subtracts the noise on the spectrum. This defines the image value of the peak. Therefore it was necessary to adapt this principle of calculation to this specific 
element composed of six isotopes: ${ }^{102} \mathrm{Pd},{ }^{104} \mathrm{Pd},{ }^{105} \mathrm{Pd},{ }^{106} \mathrm{Pd},{ }^{108} \mathrm{Pd}$ and ${ }^{110} \mathrm{Pd}$. The concentration of ${ }^{102} \mathrm{Pd}$ in the natural abundance is $1.02 \%$. This value is too small to be reliably measured and has been avoided by a previous publication [2].

The calculation applied to obtain the isotopic variation follows three steps:

1. For each spectrum, the maximum value of each pic is extracted from the raw data,

2. the noise is calculated from the data out of the range of palladium isotopes (from 111 to $112 \mathrm{AMU})$,

3. the noise is then subtracted to each maximum of each peak,

4. the global isotopic concentration is then calculated in percentage for each isotope, taking into account the absence of ${ }^{102} \mathrm{Pd}$.

Because ${ }^{102} \mathrm{Pd}(1.02 \%)$ is not evaluated in this study, the percentage is calculated on a base of 98.98 instead of 100 . This allows us to have the right image of the amount present in the sample.

5. The ratio between the standard natural abundance and the percentage of the control is applied to the results of the experimental.

Finally, because this calculation is made for the control and for the experimental cathodes the variation of percentage is the image of the effect of hydrogen loading. Then a corrected value of the experimental isotopic concentration is calculated. Figure 26 gives an example of the beginning of the calculation. The reader is highly encouraged to take a look at the complete calculation [12]. 


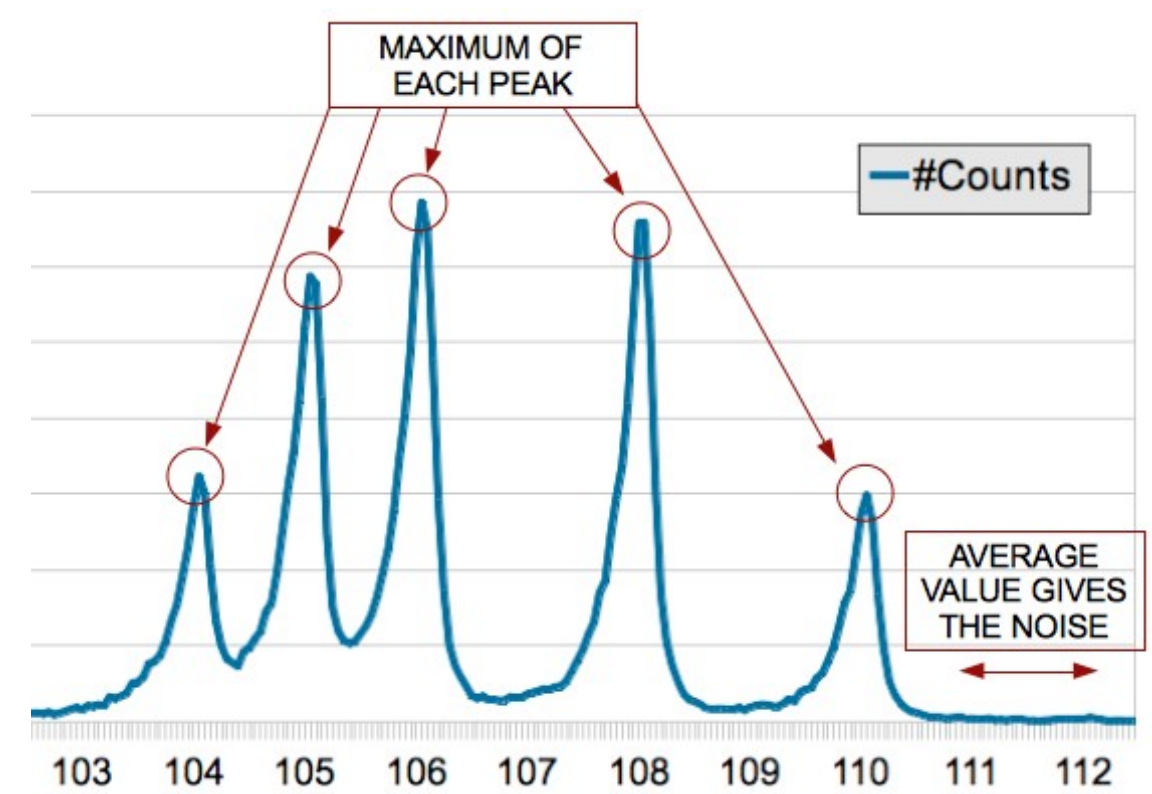

Figure 27: Example of data extraction from the measurements.

This calculation then gives the following Table 2. The first column lists the $\mathrm{Pd}$ isotopes, the second column gives the natural abundance, the third gives the calculated value for the control metal, the fourth gives the standard derivation of the control Pd percentage. The fifth the results of the experimental cell calculation. The sixth column displays the standard deviation for the experimental cathode, and the seventh the corrected value of the isotopic variation for the experimental palladium.

The results of the previous Table 2 are synthesized in the following graph. From these results, we can tell the variation of each isotope from the natural abundance and the concentration calculated previously. Hence, ${ }^{104} \mathrm{Pd}$ increased for a very small value, ${ }^{105} \mathrm{Pd}$ decreased in the same way, ${ }^{106} \mathrm{Pd}$ also decreased where ${ }^{108} \mathrm{Pd}$ and ${ }^{110} \mathrm{Pd}$ both increased. 


\section{Isotopic Concentration Before And After Experiment}

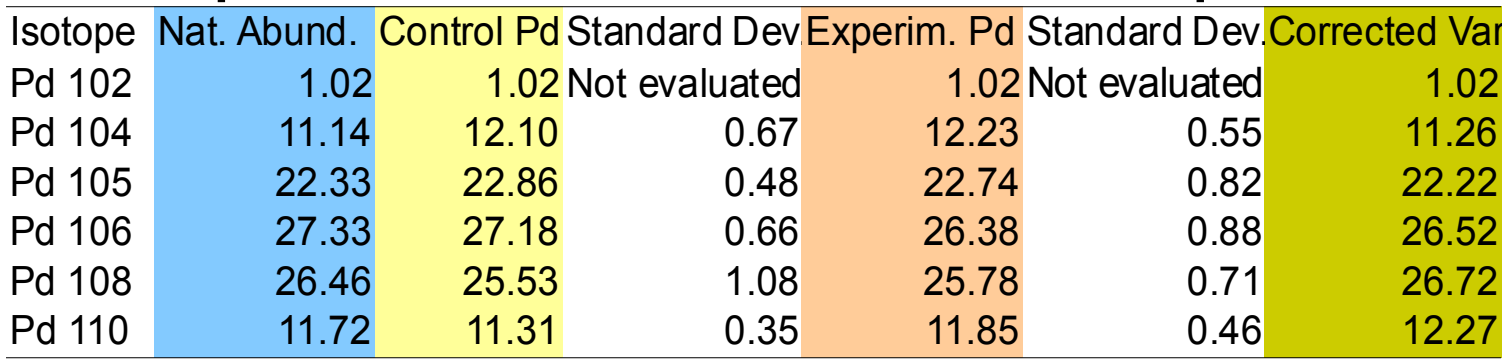

Table 2: Results of the evaluation of the isotopic concentration. The variation of ${ }^{102} \mathrm{Pd}$ is not evaluated. The last column gives the corrected value of the experimental cell following the trend given by the measurements on the control cell.

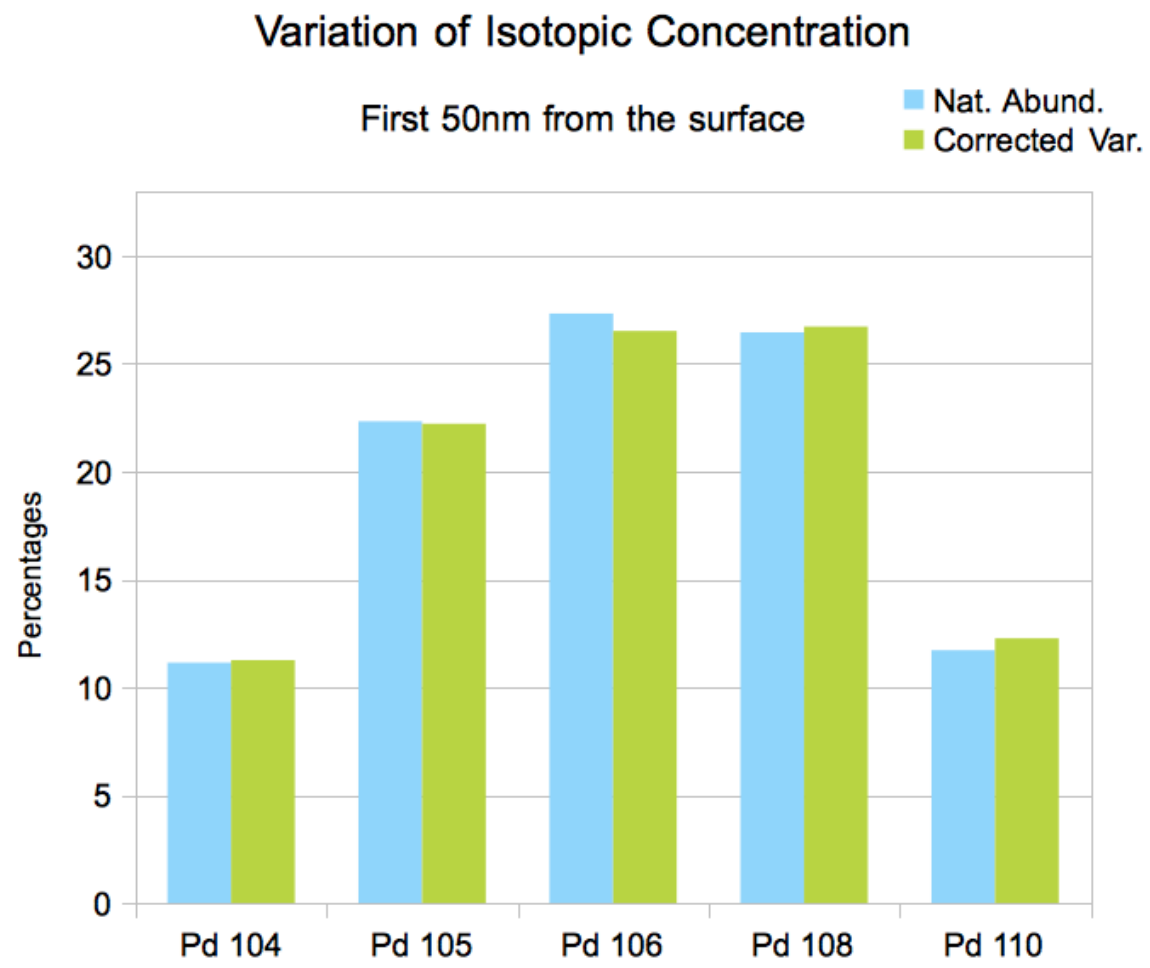

Figure 28: Graph showing the variation between the natural abundance and the calculated value of the loaded palladium. 
Finally, Figure 28 gives us the percentage change for each isotope. From this measurement, ${ }^{110} \mathrm{Pd}$ has increased the most with $5 \%$, then ${ }^{108} \mathrm{Pd}$ and ${ }^{104} \mathrm{Pd}$ increased both with $1 \%$. Then ${ }^{105} \mathrm{Pd}$ and ${ }^{106} \mathrm{Pd}$ decreased respectively $-0.5 \%$ and $-3 \%$. This type or variation can either come from the location where the palladium has been extracted or from the loading. Geologist reported a variation of isotopic abundance from one mining source to another [10] but only on tenth of per thousand of variation. On the other side the loading may induce an increase of ${ }^{106} \mathrm{Pd}$ with a deuteron which would give ${ }^{108} \mathrm{Pd}$ and show nuclear transformations in a large scale $\left({ }^{106} \mathrm{Pd}+\mathrm{D}=106+\mathrm{p}+\mathrm{n}=108\right)$. The creation of a dimer containing a palladium isotope and a deuteron is not likely possible because the energy given by the ion beam is too important to allow this. The binding energy of this kind of dimers would be in order of few $\mathrm{keV}$ maximum where the beam ionization energy reaches value close to the MeV. This orders of magnitude and the necessary quantity to produce significant changes in the measurement reduces the probability drastically.

Finally, the changes showed in this batch of measurements made on May 2011 show on location rich in ${ }^{110} \mathrm{Pd}$ and ${ }^{108} \mathrm{Pd}$ that is hard to interpret and bring clear explanation.

However, other measurements have been made on other location of the cathode, giving other results that are correlating with the previously studied paper [2]. 


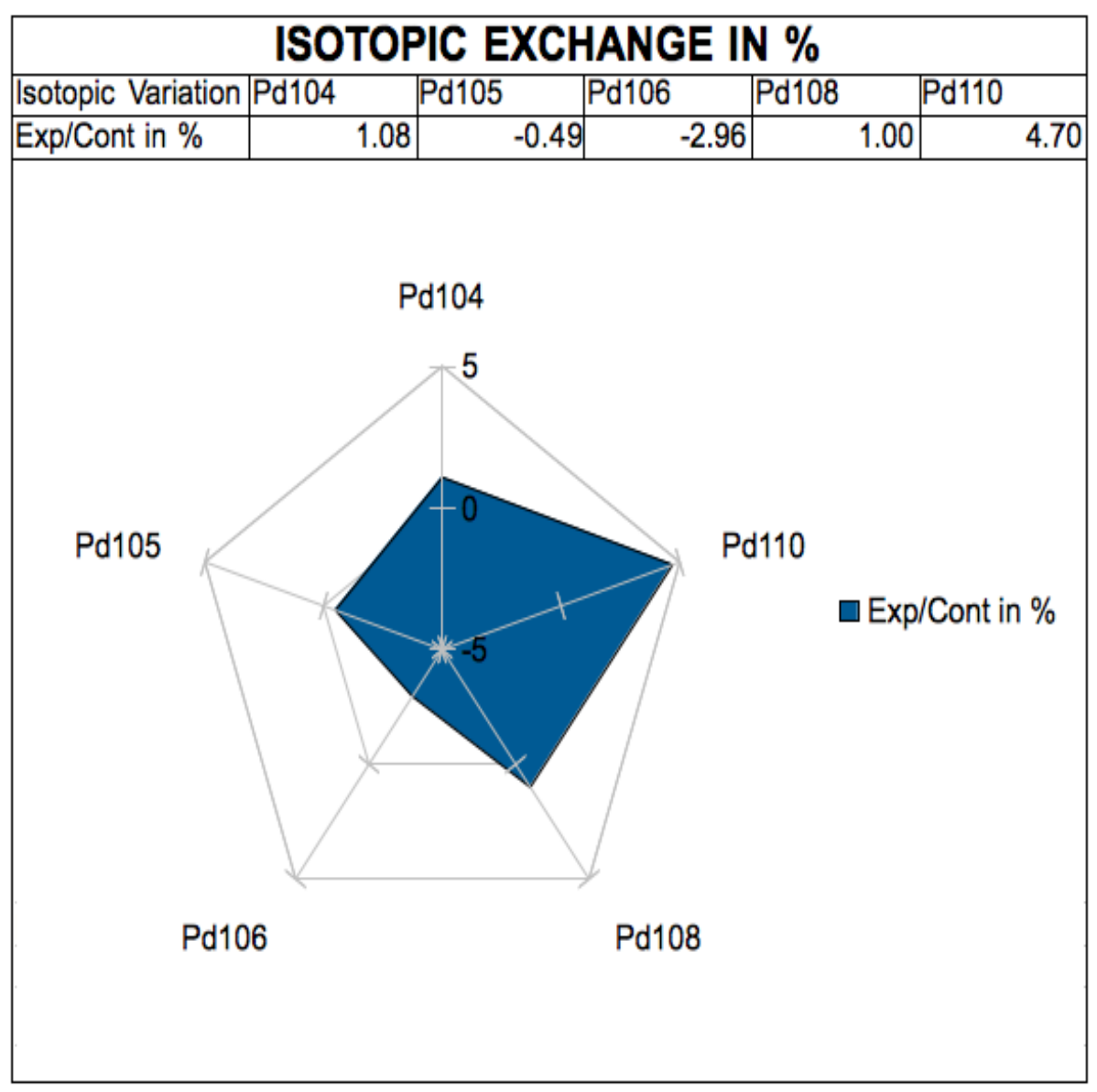

Figure 29: Graph showing the calculated isotopic exchange of Pd loaded on April 2011. This shows for each isotope the percentage exchanged between the natural abundance and the corrected value of given by the calculation.

The results given in Figure 29 were made on April 2011. These measurements went through a deeper depth. The main objective of this batch of measurement is to evaluate the qualitative composition of the sample. Hence, the spectrometer is set differently in order to cover the entire spectrum from 1 to 200 AMU. The milling dwell of measurement is also reduced to cover a wider range of the spectrum during a shorter time. Then, considering these changes and assuming the milling rate is constant, the variation of isotopic abundance is evaluated through $250 \mathrm{~nm}$ from the surface. 


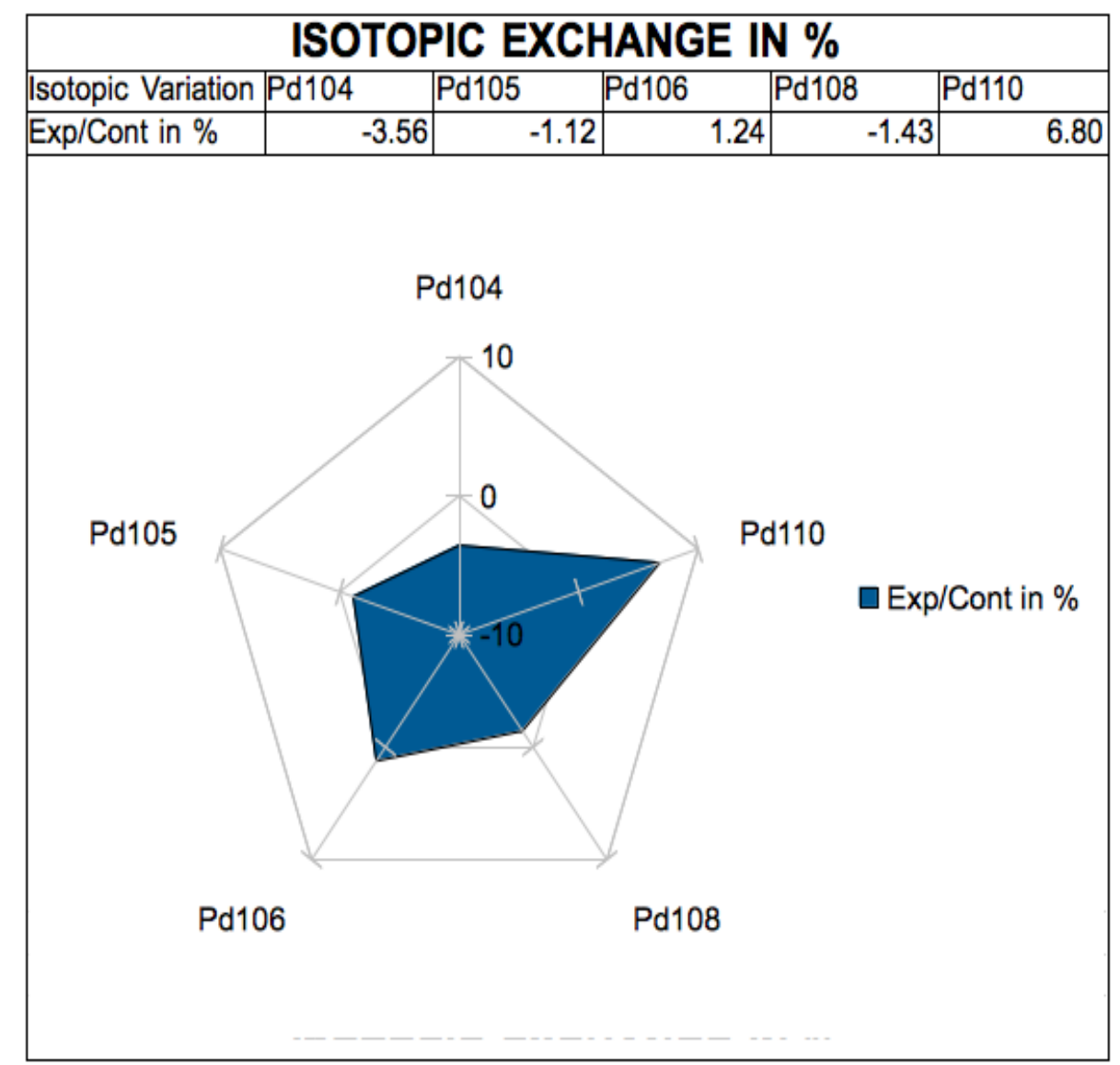

Figure 30: Graph showing the calculated isotopic exchange of loaded Pd. This shows for each isotope the percentage exchanged between the natural abundance and the corrected value of given by the calculation.

This measurement shows how this zone was less rich in ${ }^{110} \mathrm{Pd}$ and especially in ${ }^{108} \mathrm{Pd}$ than the previous batch. This value of ${ }^{108} \mathrm{Pd}$ changed from an increase in isotopic exchange to a depletion following previous results made on February 2011, giving the same clues as the paper published in 1989 by Rolison and O'Grady [2]. Their main claim was showing a depletion in ${ }^{105} \mathrm{Pd}$ and an increase in ${ }^{106} \mathrm{Pd}$. However, in their paper they described how they used and interpreted their data. The calculation was normalizing the results assuming ${ }^{110} \mathrm{Pd}$ was not impacted by combination of contamination, like dimers. In the results presented here, 
we do not follow the same principle because the changes in this isotope increase the most in every case. However, in the discussion following the paper, ${ }^{108} \mathrm{Pd}$ is showed to be increased by deuterium loading following the same trend as in the present results. All these differences in results are also due to the difference in SIMS techniques. A time of flight SIMS (ToF-SIMS) uses a different ion source, made with cesium and uses the duration of flight to characterize the mass of the secondary ions generated. In our system, a quadrupole mass analyzer interacts with the secondary ions and separates the stream generated in function of their own mass.

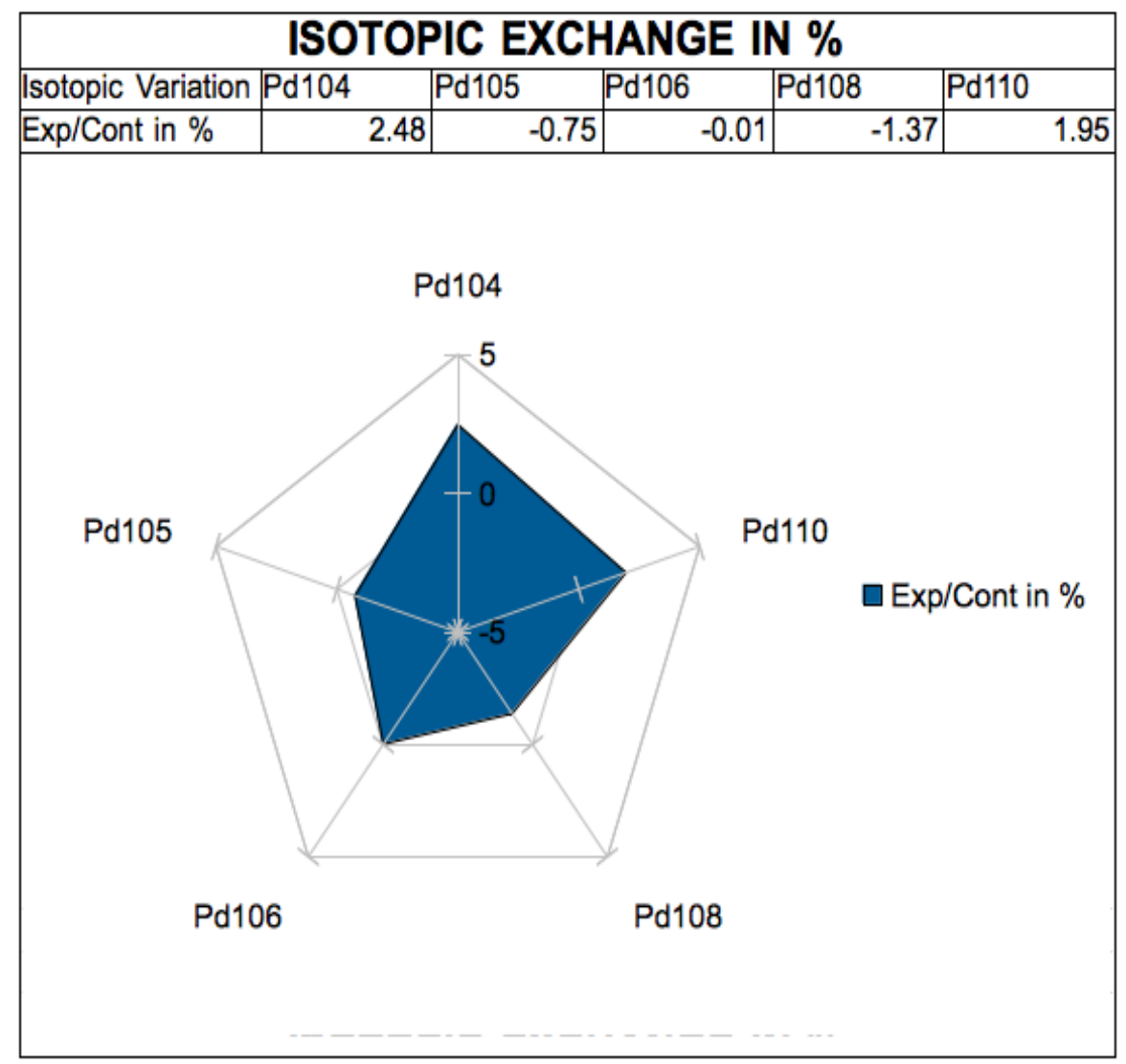

Figure 31: Graph showing the calculated isotopic exchange of Pd loaded on April 2011. This shows for each isotope the percentage exchanged between the natural abundance and the corrected value of given by the calculation. 
Finally, whereas the interpretation of Rolison was guided by concerns of contamination inside the chamber because of the use of a ToF-SIMS, our study uses a much clearer tool to produce results and it gives better flexibility in the possible interpretations. Of course, the analysis of the results presented here is not the most accurate one. But it gives another relevant way of interpretation because each spectrum first generates it own isotopic abundance, then all spectra are averaged at the end.

Figure 30, shows the results of a batch made in February 2011. The values are less reliable because at that time the noise was not minimized as it is in the previous measurements. However, we can find the same tendency of variation as in both previous measurements. ${ }^{105} \mathrm{Pd},{ }^{106} \mathrm{Pd}$ and ${ }^{108} \mathrm{Pd}$ ratios are close to the measurements made in April. The following Table 3 shows the ration between these isotopes. Because they are close and represent the three main major isotopes, the reproducibility of these measurements has more credibility.

\begin{tabular}{lccr}
\multicolumn{4}{c}{ Measurements } \\
Ratios & February 2011 & April 2011 & May 2011 \\
\hline $\mathrm{Pd}-106 / \mathrm{Pd}-108$ & 1.05 & 1.06 & 0.99 \\
\hline $\mathrm{Pd}-106 / \mathrm{Pd}-105$ & 1.23 & 1.25 & 1.19 \\
\hline $\begin{array}{l}\text { Table 3: Calculation of ratios for } \\
\text { of palladium. }\end{array}$
\end{tabular}

On this table we can see the results between February and April measurements are quite similar in trend for both ratios. However, May 2011 was milling in a ${ }^{108} \mathrm{Pd}$ rich zone and did not give the same results. 


\section{Conclusion}

Several experiment have been analyzed in the first part of the research. This part was essential to prepare and introduce some changes on the experiment. It revealed an unknown aspect of the research in low energy nuclear electrolysis. After some test and adaption of the classic system to the SIMS measurements the experiments showed some interesting phenomena like the step at the bottom of the volcano or the important release of gas from the electrode after the experiment.

The study of features brought evidence of energetic phenomenons on the surface of electrolyzed palladium with heavy water. An important variation of size in the feature has been demonstrated. Some contamination have been successfully identified by the comparative analysis made with an EDS and the SIMS. And the complementarity of this two different techniques has been showed.

The study of the isotopic variation showed a reproducibility of the measurements. Even if the study of the experiment electrolyzed with the carbon anode was not possible, the analysis successfully identified variations of the isotopic variation before and after heavy water electrolysis. This is an important step in this research and correlate with previous measurements. 


\section{References}

[1]: M. Fleischmann, S. Pons, M. Hawkins, J. Electroanalytic Chemistry. 261, 301 (1989); errata, 263, 187 (1989).

[2]: D. Rolison \& W. O'Grady - Mass/Charge Anomalies in Pd after electrochemical loading with deuterium - Section 10 in Proceedings: EPRI-NSF Workshop on Anomalous Effects in Deuterided Metals - (October 16-18, 1989) Washington, D.C.

[3]: G. Preparata - QED Coherence in matter - WorldScientific, Singapore (1995), Ch.8.

[4]: Del Giudice, E., et al. Loading of $H(D)$ in a Pd lattice. in The 9th International Conference on Cold Fusion, Condensed Matter Nuclear Science. 2002. Tsinghua Univ., Beijing, China: Tsinghua Univ. Press.

[5]: Ambadkar, A. and J. Dash, Electrolysis Of $\mathrm{D}_{2} \mathrm{O}$ With A Palladium Cathode Compared With Electrolysis Of $\mathrm{H}_{2} \mathrm{O}$ With A Platinum Electrode: Procedure And Experimental Details. 2003, Portland State University.

[6]: Violante, V., et al. Joint Scientific Advances in Condensed Matter Nuclear Science. in 8th International Workshop on Anomalies in Hydrogen / Deuterium Loaded Metals. 2007. Sicily, Italy.

[7]: National Chemical Society meeting, workshop 2009.

[8]: John Dash and Mathieu Valat (private communication, November 2010).

[9]: Gilmore, I., M.P. Seah I., International Journal of Mass Spectrometry : Ion detection efficiency in SIMS. Dependencies on energy, mass and composition for microchannel plates used in mass spectrometry. International Journal of Mass Spectrometry. 2000.

[10]: T. B. Coplen, J. K. Böhlke1, P. De Bièvre et al. Isotope-Abundance Variations Of Selected Elements Pure Appl. Chem., Vol. 74, No. 10, p. 24, (1987-2017), 2002.

[11]: FIB-611 operator manual with SIMS user documentation, FEI company.

[12]: M. Valat, LibreOffice document attached to digital publication. "SIMS analysis 110523V6.ods" 


\section{Appendix:}

\section{Certificate of Analysis AlfaAesar}

Palladium foil, 0.5mm (0.02in) thick, $99.9 \%$ (metals basis)

Stock Number: 11514

Lot Number: 105S014

Typical Analysis

$$
\text { Purity (by difference) }
$$

$99.99+\%$

$\begin{array}{llll}\mathrm{Pt} & 22 & \mathrm{Rh} & \mathrm{ND} \\ \mathrm{Ir} & \mathrm{ND} & \mathrm{Au} & 13 \\ \mathrm{Os} & \mathrm{ND} & \mathrm{Ca} & 19 \\ \mathrm{Cu} & 3 & \mathrm{Ni} & \mathrm{ND} \\ \mathrm{Mo} & \mathrm{ND} & \mathrm{Cd} & \mathrm{ND} \\ \mathrm{Pb} & \mathrm{ND} & \mathrm{Cr} & 2 \\ \mathrm{Al} & 2 & \mathrm{Mg} & \mathrm{ND} \\ \mathrm{As} & \mathrm{ND} & \mathrm{Sb} & \mathrm{ND} \\ \mathrm{Te} & \mathrm{ND} & \mathrm{B} & \mathrm{ND} \\ \mathrm{Si} & \mathrm{ND} & \mathrm{P} & \mathrm{ND} \\ \mathrm{Se} & \mathrm{ND} & & \end{array}$

Values given in ppm unless otherwise noted ND: Not detected

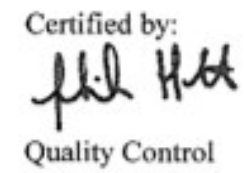

This document has been electronically generated and does not require a signature.

\section{www.alfa.com}

Tet. +1.800 .343 .5600 or

Iasis

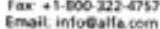

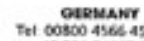

449721800002800

.49 72180009300

Eneit Evrosilewe wita cem
Unamo KINGDOM

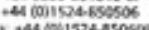

Imail UKcisterealfo con

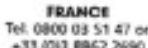

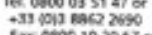

?ax 0600102067

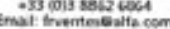

Teit +91 Molat

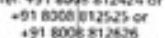

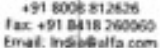

Tet + CHexis

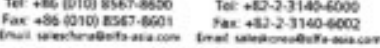

